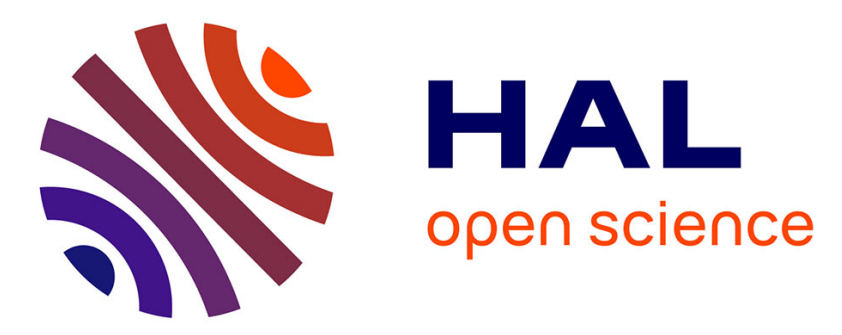

\title{
Oxidation of polyphenols and inhibition of photosystem II under acute photooxidative stress
}

\author{
Guy Samson, Zoran Cerovic, Waleed El Rouby, Pierre Millet
}

\section{To cite this version:}

Guy Samson, Zoran Cerovic, Waleed El Rouby, Pierre Millet. Oxidation of polyphenols and inhibition of photosystem II under acute photooxidative stress. Planta, 2020, 251 (1), 10.1007/s00425-019-03316x . hal-02945699

\author{
HAL Id: hal-02945699 \\ https://hal.science/hal-02945699
}

Submitted on 22 Sep 2020

HAL is a multi-disciplinary open access archive for the deposit and dissemination of scientific research documents, whether they are published or not. The documents may come from teaching and research institutions in France or abroad, or from public or private research centers.
L'archive ouverte pluridisciplinaire HAL, est destinée au dépôt et à la diffusion de documents scientifiques de niveau recherche, publiés ou non, émanant des établissements d'enseignement et de recherche français ou étrangers, des laboratoires publics ou privés. 
2 Oxidation of polyphenols and inhibition of photosystem II under acute 3 photooxidative stress

4

6

7 Guy Samson ${ }^{1, *}$, Zoran G. Cerovic ${ }^{2}$, Waleed M.A. El Rouby ${ }^{3,4}$, Pierre Millet ${ }^{3}$

$10{ }^{1}$ Groupe de Recherche en Biologie Végétale, Département des sciences de l'environnement, 11 Université du Québec à Trois-Rivières, C.P. 500 Trois-Rivières QC Canada G9A 5H7

* Corresponding author: Guy.Samson@uqtr.ca; Phone: 819-376-5011, ext. 3374;

${ }^{3}$ Institut de Chimie Moléculaire et des Matériaux d'Orsay, UMR 8182, Université Paris-Sud, Bâtiment 410 - Rue du Doyen Georges Poitou ,91400 Orsay cedex, France

${ }^{4}$ Materials Science and Nanotechnology Department, Faculty of Postgraduate Studies for Advanced Science (PSAS), Beni-Suef University, 62511 Beni-Suef, Egypt.

30

31

Fax: 819-376-5084 


\section{Abstract}

34 Main conclusion We observed a close correlation between the inhibition of photosystem II 35 and the oxidation of polyphenols during an acute oxidative stress in sunflower leaf discs.

To assess the physiological significance of polyphenols as antioxidants in planta, we compared the kinetics of polyphenols oxidation with the inhibition of the photosynthetic apparatus in sunflower leaf discs exposed to an acute photooxidative stress. Illumination of leaf discs in presence of methyl viologen induced a rapid and large non-photochemical quenching of chlorophyll- $a$ fluorescence, which was reversed after four hours of treatment as indicated by the $\approx 30 \%$ increases of the steady-state (Fs) and maximal (Fm') levels of chlorophyll- $a$ fluorescence relative to the first hour of treatment. This event coincided with the accelerated decreases of the maximum $(\mathrm{Fv} / \mathrm{Fm})$ and effective $(\Delta \mathrm{F} / \mathrm{Fm}$ ') quantum yields of photosystem II, and also with the beginning of polyphenols oxidation, estimated by the UV absorbance of methanolic leaf extracts, and supported by the Folin-Ciocalteu method and cyclic voltammetry. The decreases of Fv/Fm and the concentrations of reducing polyphenols were highly correlated $\left(\mathrm{R}^{2}=0.877\right)$ during the experiment. Coherent with the decrease of UV absorbance of methanolic extracts, polyphenols oxidation resulted in a marked decrease of UV-absorbance of leaf epidermis. Also, polymerization of oxidized polyphenols caused the accumulation of brown pigments in the MVtreated leaf discs, decreasing leaf reflectance, especially at 550 and $740 \mathrm{~nm}$. Fluorescence intensities were also decreased during the MV-treatment. Interestingly, the emission fluorescence ratio $\mathrm{F}^{740} / \mathrm{F}^{684}$ (excitation at $550 \mathrm{~nm}$ ) decreased similarly to $\mathrm{Fv} / \mathrm{Fm}\left(\mathrm{R}^{2}=0.981\right)$ due to the brown pigments. Moreover, the excitation fluorescence ratio $\mathrm{F}_{484} / \mathrm{F}_{680}($ emission at $740 \mathrm{~nm}$ ) was linearly correlated $\left(\mathrm{R}^{2}=0.957\right)$ to $\Delta \mathrm{F} / \mathrm{Fm}$ ', indicating a decrease of efficiency of energy transfer between the antenna pigments to the photosystem II reaction center during the oxidative stress. These results support the view that polyphenols can be effective antioxidants protecting the plants 58 against reactive oxygen species. 
Polyphenols (PPs) are specialized metabolites in plants that are essential for their successful interactions with the environment. By their structural diversity and different localizations, PPs fulfil multiple functions such as deterrent against herbivores, barriers against pathogens, aid in pollen and seed dispersal, and molecule signals for symbiotic relations with microorganisms (Treutter 2005; Ghasemzadeh and Ghasemzadeh 2011; Mandal et al. 2010). PPs also contribute to plant tolerance against a wide range of abiotic stresses, like UV, high light intensities, drought, salinity, heavy metals, air pollution, mechanical wounding, and nitrogen limitation (Dixon and Paiva 1995; Nakabayashi and Saito 2015; Treutter 2005). Besides their specific targets, all these stresses have in common to accelerate the production of reactive oxygen species (ROS) leading to oxidative stress.

Widely accepted but not fully demonstrated, the role of PPs as antioxidant in planta is inferred from several observations. PPs show antioxidant capacity in vitro, and their concentrations increase in plants exposed to the above-mentioned stresses (Dixon and Paiva 1995). Among the stress-induced PPs, there is a preferential accumulation of strong antioxidants notably quercetin, with its o-dihydroxy B-ring compared to the monohydroxy B-ring kaempferol (Agati et al. 2012; Edreva 2005). High flavonoid content was related to higher viability in senescent Vitis vinifera suspension cell cultures by quenching ROS, hence limiting the signalling cascade leading to programmed cell death (Bertolini et al. 2016). Moreover, the antioxidative role in planta of PPs is supported by Arabidopsis mutants that overaccumulate flavonoids with strong antioxidant capacity. Compared to the wild-type Col-0, these mutants showed higher tolerance to observations can be made with salicylic acid. This plant growth regulator improves plant tolerance to a wide range of abiotic stresses (Hayat et al. 2010), and it was shown to enhance PPs concentrations in plants (Kováčik et al. 2009), plant cell cultures (Dong et al. 2010) and algal cultures (Kováčik et al. 2010).

Under intense and transient stress conditions and under high light intensities, excess of $\mathrm{H}_{2} \mathrm{O}_{2}$ generated in the chloroplasts that is not scavenged by the ascorbate-glutathione cycle diffuses to the vacuoles. There, class-III peroxidases can catalyse $\mathrm{H}_{2} \mathrm{O}_{2}$ reduction to $\mathrm{H}_{2} \mathrm{O}$ by using PPs, mostly flavonoids and hydroxycinnamates, as electron donors. The resulting phenoxyl radicals are normally re-reduced by ascorbate, the latter being regenerated in the cytosol by gluthation and NADPH. This peroxidase/polyphenol/ascorbate system is efficient as long as the cytosolic ascorbate pool is not depleted: at this point, the phenoxy radicals accumulate and react with other radicals, amino acids or proteins, to polymerize into complex brown pigments (Pérez et al. 2002; Pourcel et al. 2007; Takahama 2004; Yamasaki et al. 1997).

One of the missing evidences required to confirm the physiological significance of PPs as antioxidants is the presence of a spatio-temporal correlation between the extent of oxidative stress and the oxidation of PPs (Agati et al. 2012; Hernández et al. 2009). Oxidation of PPs in planta and the accumulation of brown pigments is common during plant development, causing for instances the browning of seed coats, onion scales, heartwood (Pourcel et al. 2007; Takahama 2004), and aging tobacco leaves (Takahama 2004). But during oxidative stress, there are only few 
reports of PPs oxidation in leaves (Agati et al. 2007; Hernández et al. 2006), in contrast with the numerous studies mentioned above showing their accumulation during plant acclimation to chronic environmental stress. Simultaneous decreases of the levels of phenolics and chlorophylls were observed during foliar senescence in Kalanchoe pinnata (Jaiswal et al. 2012). Meir et al. (1995) made similar observations during senescence of leaf discs from various edible herbs, i.e. similar decreases of chlorophyll contents and "aqueous reducing compounds", which phenolic acids and flavonoids were considered as the main components. In another study, Arabidopsis leaves wild type and mutants with different anthocyanin contents were illuminated in presence of methyl viologen (Shao et al. 2008). Photosynthetic reactions estimated from chlorophyll fluorescence parameters decreased in a triphasic pattern, to be nearly abolished after 3 to 4.5 hours of illumination depending on the anthocyanin contents. In contrast, total phenolics and flavonoids, estimated from UV absorbance of methanolic extracts, decreased more or less linearly by 10 to $25 \%$ only after 12 hours of treatments. In that experiment, vacuum infiltration of methyl viologen into the leaves may have lowered $\mathrm{O}_{2}$ concentrations, and the brown pigments resulting from the oxidation products of leaf phenolics were not monitored.

In this context, there is a need to further characterize the relation between the oxidation of PPs in leaves with the physiological damages occurring during an acute oxidative stress. To this end, we illuminated sunflower leaf discs in presence of methyl viologen and correlated the inhibition of photosynthetic electron transport with the oxidation of PPs estimated from leaf methanolic extracts by three independent methods, notably cyclic voltammetry. This method is frequently used as a direct indicator of reducing capacity of PPs in food and beverage research, especially on wine and teas (Kilmartin and Hsu 2003; Kilmartin et al. 2001), but has not been used previously to characterise PPs in leaf extracts in relation to photosynthetic activity and photooxidative stress. We also monitored by reflectance and fluorescence spectroscopy the impacts of accumulating brown pigments on leaf optical properties. The results show a close temporal correlation between the oxidation of PPs and the loss of integrity of the photosynthetic electron chain.

\section{Material and Methods}

\section{Plant material}

Dwarf sunflower plants (Helianthus annuus L., var. Sunspot) were grown during eight weeks in a growth chamber. The photoperiod was $16 \mathrm{~h} / 8 \mathrm{~h}$ and the day light intensity (PFD) was $150 \mu$ moles photons $\mathrm{m}^{-2} \mathrm{~s}^{-1}$. The day/night temperatures were $25^{\circ} / 17^{\circ} \mathrm{C}$. Plants received tap water as required and appropriate amount of NPK 20-20-20 fertilizer once a week.

Just before the experiments, discs $(2.2 \mathrm{~cm}$ diam.) were cut with a cork borer from nonshaded and horizontally oriented areas of the $4^{\text {th }}$ to $6^{\text {th }}$ leaves, and avoiding the midribs. Discs were kept between moist paper towels until the beginning of the treatments. PPs contents in leaf discs were estimated just before the experiments with a Dualex Scientific (Force-A, Orsay, 
144 France) leaf-clip sensor. To minimize the variations due to leaf development, only leaf discs with 145 Dualex Flv values between 0.6 and 0.8 were used for the experiments.

\section{Treatments}

Leaf discs were floated with their abaxial side in contact with distilled water containing 0 or 0.4 $\mathrm{mM}$ methyl viologen (MV), and maintained in the growth chamber under the same PFD and temperature as the growth conditions. During the experiment, six discs were taken after 0, 3, and 7 hours for the control, and after 1, 2, 4, 6, and 8 hours for the MV treatment. At each hour, the following measurements described below were sequentially made within 30-40 minutes: modulated chlorophyll-a fluorescence, Multiplex 330 fluorescence, reflectance spectra, and fluorescence spectra. Then, the discs were stored at $-18^{\circ} \mathrm{C}$ for less than two weeks for pigments and PPs analysis. The whole experiment was repeated twice.

\section{Modulated chlorophyll-a fluorescence}

Pulse-amplitude modulated chlorophyll- $a$ fluorescence was measured from leaf discs with a MINI-PAM fluorometer (Walz, Germany). For each disc, the stationary fluorescence level Fs was measured under the same ambient light intensity $\left(150 \mu\right.$ moles photons $\left.\mathrm{m}^{-2} \mathrm{~s}^{-1}\right)$ and then the maximum Fm' was induced by a $1 \mathrm{~s}$ saturating flash. From the Fs and Fm', the effective quantum yield of photochemistry of Photosystem II (PSII) $\Delta \mathrm{F} / \mathrm{Fm}$ ' was calculated, where $\Delta \mathrm{F}=\mathrm{Fm}$ '- Fs (Klughammer and Schreiber 2008).

To not interfere with the time course of the MV-induced photooxidative stress, a separate experiment was done to measure the changes of the maximum quantum yield of photochemistry of PSII during the experiment. At each hour during the treatments, leaf discs were placed in darkness for 40 minutes before the minimum Fo level was measured and then, the maximum Fm was induced by a $1 \mathrm{~s}$ saturating flash. The maximum quantum yield of PSII photochemistry Fv/Fm was calculated, where Fv = Fm- Fo.

\section{Reflectance}

To follow the accumulation of brown pigments resulting from the oxidation of PPs, reflectance spectra from $360 \mathrm{~nm}$ to $740 \mathrm{~nm}$ (10 nm intervals) were measured on the adaxial side of leaf discs with a portable spectrophotometer CM-2600d (Konica Minolta, Roissy, France).

In a separate experiment, reflectance spectra were measured as described above on depigmented leaf discs, which had been exposed 8 hours with 0 or $0.4 \mathrm{mM} \mathrm{MV}$, and then incubated in methanol at $4^{\circ} \mathrm{C}$ for 24 hours. 


\section{Fluorescence spectroscopy}

The consequences of PPs oxidation on leaf optical properties were also monitored during the experiment by recording the excitation and emission chlorophyll- $a$ fluorescence spectra with a spectrofluorometer Cary Eclipse (Varian, Les Ulis, France). The discs were placed in a leaf holder positioned at $60^{\circ}$ from the excitation source and $30^{\circ}$ from the detector side. Fluorescence emission and excitation spectra were recorded with a bandwidth of $10 \mathrm{~nm}$ on both the excitation and the emission side, and a scan rate of $120 \mathrm{~nm} \mathrm{~min}^{-1}$. Fluorescence emission was recorded from 650 to $800 \mathrm{~nm}$, excited at $550 \mathrm{~nm}$, with the additional short-pass and long-pass protection filters, SP600 (Edmund Scientific) and RG630 (Schott), respectively. Fluorescence excitation spectra from 390 to $680 \mathrm{~nm}$, emitted at $740 \mathrm{~nm}$, were recorded with the additional filters SP700 (Schott) and RG715 (Schott), on the excitation and emission side, respectively. Fluorescence excitation spectra from 300 to $390 \mathrm{~nm}$, emitted at $740 \mathrm{~nm}$, were recorded with the DUG11 (Schott) and RG715 (Schott) filters, on the excitation and emission side, respectively. All spectra were corrected for the response of detectors and transmission of monochromators and filters as described in Louis et al. (2006). Throughout the manuscript fluorescence excitation wavelengths are indicated by subscripts and fluorescence emission wavelengths, by superscripts.

The Multiplex 330 (FORCE-A, Orsay, France) proximal sensor was also used to measure instantaneously fluorescence from the whole surface of leaf discs. This photodiode- and filterbased sensor records chlorophyll- $a$ fluorescence like the MINI-PAM, but simultaneously at two emission bands, centered at 684 and at $740 \mathrm{~nm}$, with LED-excitation centered at 330, 450 and 630 nm.

\section{Measurements of pigment and polyphenol concentrations}

Leaf discs were cut into small pieces with a scalpel and incubated overnight in pure methanol at $4^{\circ} \mathrm{C}$ in the dark. The extracts were filtered and the absorbance spectra from 220 to $800 \mathrm{~nm}$ were recorded with an Agilent/HP 8453 spectrophotometer (Hewlett Packard, Les Ulis, France). Chlorophyll $a+b$ concentrations were calculated according to Lichtenthaler (1987).

The levels of soluble PPs were first estimated by the UV absorbance of the methanolic extracts after subtraction of chlorophylls contribution, calculated from spectra of pure chlorophyll- $a$ and chlorophyll- $b$ as described by Ounis et al. (2001). PPs concentrations were also estimated by the Folin-Ciocalteu method (Prior et al. 2005). In brief, $1 \mathrm{ml}$ of the methanolic extract was added to $2.25 \mathrm{ml}$ of diluted Folin-Ciocalteu reagent $(0.2 \mathrm{~N})$. After six minutes, 1.75 $\mathrm{ml}$ of saturated $\mathrm{Na}_{2} \mathrm{CO}_{3}$ was added, and the mixture was incubated for two hours, and then centrifuged. The absorbance of the supernatants was read at $760 \mathrm{~nm}$. A calibration curve $\left(\mathrm{R}^{2}=0.998\right)$ was made using the same procedure with nine concentrations of gallic acid (from 0.25 to $50 \mathrm{mg} \mathrm{L}^{-1}$ ). 


\section{Cyclic voltammetry}

217 Cyclic voltammetry was used to clearly illustrate the oxidation of leaf PPs. For these 218 measurements, higher PPs concentrations in leaf methanolic extracts were required. So, a distinct 219 experiment was done where discs were treated identically as described above in presence or 220 absence of MV for eight hours. For both treatments, 3 groups of eight leaf discs were made, and 221 each group was incubated in $40 \mathrm{~mL}$ of methanol at $65^{\circ} \mathrm{C}$ for 20 minutes, followed by a second 222 incubation in 15 minutes in $20 \mathrm{~mL}$ methanol. For each group, the two extracts were pooled, and 223 concentrated in a roto-evaporator to a final volume of $5 \mathrm{~mL}$.

Methanolic extracts $(1 \mathrm{~mL})$ were introduced in a three-electrodes cell containing $1 \mathrm{ml}$ of 0.2 diameter), an $\mathrm{Ag} / \mathrm{AgCl}$ electrode, and a glassy carbon plate were used as working, reference and counter electrodes respectively. Argon was bubbled for several minutes in the solution to remove dissolved air. Cyclic voltammograms were recorded using a Voltalab PGZ 100 potentiostat, at a scanning rate of $50 \mathrm{mV} / \mathrm{s}$, over the potential window from -100 to $500 \mathrm{mV}$ vs. $\mathrm{Ag} / \mathrm{AgCl}$. All electrode potentials were read against the reference electrode of $\mathrm{Ag} / \mathrm{AgCl}$. Before each measurement, the glassy carbon working electrode was gently polished with an aluminum powder solution on an abrasive surface for $2 \mathrm{~min}$ and then sonicated also for $2 \mathrm{~min}$. The cell and the electrodes were washed with deionized water (milliQ grade, Millipore) between each experiment. Reducing equivalent contents expressed in microcoulomb $(\mu \mathrm{C})$ were determined by first calculating the area under the curve "current versus voltage", and then dividing this surface area (in $\mu \mathrm{AmV}$ or $\mu \mathrm{C} \mathrm{s}^{-1} \mathrm{mV}$ ) by the constant scanning rate (here $50 \mathrm{mV} \mathrm{s}^{-1}$ ) (Kilmartin and Hsu 2003).

\section{Statistical analysis}

241

For each dependent variable measured, descriptive statistics (means and standard errors of the mean) and analyses of variance were calculated with the SYSTAT software (SPSS, Chicago IL.). The factors (independent variables) were "hours" (i.e. with or without MV) and "experiments". For all dependent variables tested, highly significant effects $(p<0.01)$ of MV (hours) were 246 effects of MV on the different variables were observed in the two experiments.

\section{Results}


254 Characterization of methyl viologen effects on photosynthetic electron transport and photosynthetic pigments

256 Exposure of sunflower leaf discs to MV $0.4 \mathrm{mM}$ under a white light of $150 \mu$ mole $\mathrm{m}^{-2} \mathrm{~s}^{-1}$ for 8 treatment, $\Delta \mathrm{F} / \mathrm{Fm}$ ' decreased from about 0.7 to 0.3 and then remained stable for 2 hours, before it further decreased close to 0 between 4 and 8 hours of treatment (Fig. 1a). In contrast, the decrease of Fv/Fm due to the presence of MV was biphasic: it remained little affected during the first two hours, and decreased afterward down to 0.2 (Fig. 1b).

The decrease of $\Delta \mathrm{F} / \mathrm{Fm}$ ' in the first half of the treatment could be related to the formation of a large non-photochemical quenching (NPQ), as Fm' was strongly quenched (Fig.1c) while Fs remained similar to the control values (Fig.1d). The Fs and Fm' values transiently increased at 4 hours, indicating the collapse of the NPQ and the subsequent loss of integrity of the photosynthetic electron transport system.

Fig. 2 shows that despite its strong effect on photochemical reactions, MV did not affect significantly the concentrations of chlorophyll $a+b$ and of carotenoids throughout the experiment.

\section{Polyphenol oxidation during MV-induced oxidative stress estimated from leaf extracts}

To determine if the losses of PSII photochemical efficiency were correlated to the oxidation of PPs in MV-treated leaf discs, we analysed the spectra of methanolic extracts from which chlorophylls $a$ and $b$ absorbance was subtracted as in Ounis et al. (2001) (Fig. 3a). The control spectrum shows the typical absorbance of carotenoids in the blue region, and the UV absorbance peak near $328 \mathrm{~nm}$ is characteristic of hydroxycinnamates (Stelzner et al. 2019). The MV treatment caused a decrease of the UV absorbance accompanied by a large increase in the violet region. These opposite changes are typical of phenolic oxidation (Ramešová et al. 2015; Sokolová et al. 2012). Also, the increase of absorbance at $420 \mathrm{~nm}$ is a common indicator of et al. 1999; Tomás-Barberán et al. 1997).

The absorbance at $328 \mathrm{~nm}$ decreased in a biphasic manner during the MV-treatment: A328 decreased slightly in the first two hours, before a more pronounced decline between 4 and 8 hours. After eight hours of MV-treatment, A328 accounted for $56 \%$ of the control values (Fig. $3 \mathrm{~b})$. The increase of absorbance near $420-440 \mathrm{~nm}$ is prominent but the spectra are noisy due to the large absorbance of chlorophylls in that region, close to the sensitivity limit of the spectrophotometer (see original spectra in Fig S1).

The oxidation of PPs monitored by the decrease of A328 was supported by the contents of reducing PPs (gallic acid equivalents, GAE) estimated with the Folin-Ciocalteu method: we 290 observed a small decrease of GAE in the first two hours, followed by a larger decline after 4 
hours (Fig. 3c). At the end of the treatment, the GAE in MV-treated discs represented $67 \%$ of the control values. There is a close correlation $\left(\mathrm{R}^{2}=0.934\right)$ between the estimations of PPs contents by the Folin-Ciocalteu method and the absorbance at $328 \mathrm{~nm}$.

The Folin-Ciocalteu method estimates the overall capacity of PPs (and other antioxidants) to reduce the molybdo-tungsto-phosphoric heteropolyanion (Prior et al. 2005). So, we used cyclic voltammetry to provide a more detailed illustration of the loss of the reducing capacity of PPs in extracts from MV-treated leaf discs. Cyclic voltammograms shown in Fig. 4 are plots of the cell current as a function of the potential (in $\mathrm{mV}$ vs. $\mathrm{Ag} / \mathrm{AgCl}$ ) of the working electrode, measured on the methanolic extracts from control and MV-treated leaf-discs. Peak currents (y-axis) are proportional to the concentration of reducing-active components in the extracts. Peak potentials (along the x-axis) indicate the potential at which the species donate their electrons. The curve of MV-treated leaf-discs is markedly lower than the control curve above $100 \mathrm{mV}$. The antioxidant capacity of the samples can be estimated by the area under the curve, from which we calculated the number of charges passed during the oxidative scanning from -100 to $500 \mathrm{mV}$. A value of $1285 \mu \mathrm{C}$ was obtained for the control, and a value of $778 \mu \mathrm{C}$ for leaf discs treated with $\mathrm{MV}$ during eight hours, i.e. $60 \%$ of the control value.

\section{Polyphenol oxidation monitored in situ by alterations of leaf discs optical properties}

\section{Reflectance}

The treatment of leaf discs with MV caused their browning that became visually apparent in the second half of the experiment. To characterize these changes, reflectance spectra of leaf discs were measured throughout the experiment. The most noticeable effect of the MV-treatment is the flattening of the spectra, with decreased reflectance that is more evident in the far-red and green regions, i.e. where chlorophylls absorb less (Fig. 5a). The red-edge, i.e. the position of the sharp reflectance increase, remained unchanged. Reflectance at $740 \mathrm{~nm}$ was little affected until the $4^{\text {th }}$ hour of treatments, and then it decreased to $52 \%$ of the control value (Fig. $5 \mathrm{~b}$ ). In the blue and red regions of the spectra, reflectance decreased between 0 and 4 hours, but then increased slightly.

Reflectance spectra of leaf discs depigmented after their incubation in methanol were also measured (Fig. 6). Much higher reflectance values are seen in control than MV-treated depigmented leaf discs, showing that that the browning of MV-treated leaf discs is caused by the accumulation of insoluble brown pigments following the polymerization of oxidised PPs (Takahama 2004; Yamasaki et al. 1997).

\section{Fluorescence emission spectra}

Considering the loss of non-photochemical quenching, the decrease of UV-absorbing PPs and the accumulation of brown pigments during MV-treatment, fluorescence spectroscopy can be a powerful tool to detect oxidative stress in leaves. So we firstly measured emission spectra of chlorophyll- $a$ fluorescence excited at $550 \mathrm{~nm}$ (Fig. 7a). In the first two hours, the intensity of the fluorescence peak at $740 \mathrm{~nm}$ was slightly decreased by the MV-treatment (Fig. 7b). Then, the $\mathrm{F}^{740}$ 
intensity increased at 4 hours, reminiscent of the enhanced Fs level observed at that time (Fig. 1c), before it decreased by more than $50 \%$ after 6 and 8 hours.

Not only the intensity but also the shape of the spectra was affected by the MV-treatment, as seen by the fluorescence ratio $\mathrm{F}^{740} / \mathrm{F}^{684}$ (Fig. $7 \mathrm{c}$ ). The $\mathrm{MV}$ effect on the $\mathrm{F}^{740} / \mathrm{F}^{684}$ ratio was biphasic: it remained unaffected during the first two hours, and then decreased from 4.30 to a value of $2.28,53 \%$ relative to the control. Interestingly, the changes of Fv/Fm (Fig. 1c) and $\mathrm{F}^{740} / \mathrm{F}^{684}$ during the MV treatment were highly correlated $\left(\mathrm{R}^{2}=0.981\right)$.

\section{Fluorescence excitation spectra}

Fluorescence excitation spectra can provide useful information about light absorption and energy transfer by the antenna pigments, processes that could be affected by the PPs oxidation and the losses of PSII photochemical efficiency during the MV-oxidative stress. The excitation spectrum of control leaf discs shows two pronounced peaks, one at 420 that can be assigned to excitation of Chl- $a$, and the other at $484 \mathrm{~nm}$, associated to the energy transfer from the accessory pigments chlorophyll- $b$ and xanthophylls to chlorophyll- $a$ (Zeng et al. 2016) (Fig. 8a). There are also minor Qx bands visible between 500 and $600 \mathrm{~nm}$. In spectra from leaf discs exposed MV, the averaged fluorescence intensity $\mathrm{F}^{740}$ excited over 390 and $680 \mathrm{~nm}$ decreased similarly to Fs and $\mathrm{F}^{740}$ : a small decrease in the first two hours, then an increase at the fourth hour before a pronounced decrease beyond that time. More interestingly, the shape of the $\mathrm{F}^{740}$ excitation spectra was significantly altered: larger decreases occurred in the blue, especially the peaks at 420 and $484 \mathrm{~nm}$, compared to the red region of the spectrum. The Qx bands between 500 and $600 \mathrm{~nm}$ were strongly suppressed in MV-treated leaf discs.

Since the fluorescence peak at $484 \mathrm{~nm}$ can be related to the energy transfer between the antenna pigments (Zeng et al. 2016), we calculated the ratio of the fluorescence intensities at 484 $\mathrm{nm}$ over $680 \mathrm{~nm}$ as a potential indicator of the efficiency of energy transfer from the antenna pigments to the reaction center of PSII. The results show that during the MV-treatment, the $\mathrm{F}_{484} / \mathrm{F}_{680}$ decreased strongly during the first hour, less between one and four hours, and then more rapidly after the fourth hour (Fig. 8b). Interestingly, the changes of $\mathrm{F}_{484} / \mathrm{F}_{680}$ are closely correlated $\left(\mathrm{R}^{2}=0.957\right)$ to the values of $\Delta \mathrm{F} / \mathrm{Fm}$ ' measured after different times of treatment with MV (Fig. $8 \mathrm{c})$.

Compared to the chlorophyll- $a$ fluorescence $\left(\mathrm{F}^{740}\right)$ excited by visible light, the intensity of UV-excited chlorophyll- $a$ fluorescence was relatively weak (Fig. 8a). But in a marked contrast, its intensity increased during the MV-treatment (Fig. 8d) presumably due to a loss of epidermal PPs.

\section{Multiplex 330 fluorescence measurements}

To better document the increase of UV-induced chlorophyll-a fluorescence during the MVtreatment, far-red fluorescence (FRF) intensities were measured from control and MV-treated leaf discs with a portable fluorometer Multiplex 330. This sensor has an additional excitation wavelength $330 \mathrm{~nm}$ close to the absorption maximum of hydroxycinnamates. The intensities of the FRF induced by blue excitation (Fig. 9a) followed the same patterns during the experiment as 
for the Fs (Fig. 1c) and the $\mathrm{F}^{740}$ excited at $550 \mathrm{~nm}$ (Fig. 7b) measurements made with different fluorometers. Also, the Multiplex measurements of FRF induced by UV (330 nm) markedly increased during the MV-treatment (Fig. 9b), strongly supporting the measurements made with the Cary spectrofluorometer (Fig. 8d).

The logarithm of the ratio of the FRF intensities induced by blue and UV excitations $\left(\log \left(\mathrm{FRF}_{\mathrm{BLUE}} / \mathrm{FRF}_{\mathrm{UV} 330}\right)\right.$ or $\left.\operatorname{LogFER}\right)$ is a good estimate of the epidermal UV-absorbance due to the presence of soluble PPs (Cerovic et al. 2002). The LogFER values remained stable during the first four hours, and then declined to $53 \%$ of the control value after eight hours of MV-treatment (Fig. 9c).

\section{Discussion}

The role of PPs as antioxidants in planta is inferred from several circumstantial evidences, but direct observations of their oxidation co-occurring with physiological damages during oxidative stress are still lacking. The difficulty to demonstrate such correlation arises in part from the variations of reducing PPs concentrations during normal plant development (Louis et al. 2012; Louis et al. 2009) and during plant acclimation to chronic environmental stress (Dixon and Paiva 1995; Treutter 2005). So we induced an acute oxidative stress in sunflower leaf discs that were exposed to MV $(0.4 \mathrm{mM})$ under their growth light intensity for up to eight hours. Near the fourth hour of the MV-treatment, there was a collapse of the non-photochemical quenching (NPQ) and an accelerated decline of the photochemical efficiencies of PSII. This loss of integrity of the photosynthetic reactions concurred with the beginning of PPs oxidation monitored by different methods in leaf methanolic extracts, and supported in situ by changes in leaf optical properties.

Under our experimental conditions, the effects of MV on photosynthetic electron transport in sunflower leaf discs can be described in three distinct phases. First, MV caused a rapid decline of the effective PSII quantum yield (occurring within five minutes, results not shown), followed by a second phase where $\Delta \mathrm{F} / \mathrm{Fm}$ ' remained stable or even slightly increased for up to two hours. This second phase is characterized by the presence of a large NPQ as seen by the marked decrease of Fm', which could recover after a dark period of 40 minutes (Fv/Fm remained unaffected). This large NPQ would result from the acidification of the thylakoid lumen (Derks et al. 2015). Indeed, lower production of NADPH relative ATP due to the diversion by MV of electrons from PSI to $\mathrm{O} 2$ restricts the Calvin Cycle, decreases ADP+Pi concentrations due to lower ATP utilization, and thereby impedes photophosphorylation. Then the third phase of the MV effects began around the fourth hour by transient increases of Fs and Fm', followed by their quenching below their initial values. These transient increases suggest the collapse of the NPQ as if the thylakoid membranes became suddenly permeable to $\mathrm{H}^{+}$due to oxidative damages. This effect accelerated the declines of the PSII quantum yields $\mathrm{Fv} / \mathrm{Fm}$ and $\Delta \mathrm{F} / \mathrm{Fm}$ '. It is noteworthy that the inhibition of the photosynthetic electron transport during the eight hours of MV-induced oxidative stress occurred before any significant decrease in the concentrations of the photosynthetic pigments. 
Similar triphasic patterns of MV effects on photosynthetic electron transport were reported previously by Shao et al. (2008). They observed, however, in some phenotypes of Arabidopsis leaves a large recovery of $\Delta \mathrm{F} / \mathrm{Fm}$ ' during the second phase of the MV effects. The origin of this difference is unknown but such increase could be explained notably by the actinic PFD during the MV-treatment in their experiments, which was 6 times higher than the growth PFD, as well as the absorption of MV into the leaves by vacuum infiltration.

The turning point of the MV-treatment in sunflower leaf discs could be the loss of integrity of the photosynthetic apparatus at the fourth hour, indicated by the collapse of NPQ. This collapse coincides with the accelerating rates of PPs oxidation in sunflower leaf discs. Indeed, the values of Fv/Fm (Fig. 1b) and of the A328 (Fig. 3b) values during the MV-treatment are highly correlated $\left(\mathrm{R}^{2}=0.877\right)$. The 4-hour delay before the acceleration of PPs oxidation is coherent with the model where $\mathrm{H}_{2} \mathrm{O}_{2}$ generated in chloroplasts, mitochondria or peroxisomes diffuses into the vacuoles, even those of epidermal cells, to be scavenged in a reaction catalysed by class-III peroxidases using PPs as electron donors. The oxidized PPs would be re-reduced by ascorbate, as long as ascorbate is regenerated from dehydroascorbate in the cytosol by gluthation and NADPH (Pérez et al. 2002; Takahama 2004). According to this model, it appears that under our experimental conditions, this $\mathrm{H}_{2} \mathrm{O}_{2}$ peroxidase/polyphenol/ascorbate scavenging cycle could operate during four hours before the reducing capacity to regenerate ascorbate become exhausted, overwhelmed by the high rate of ROS production, and then the oxidized PPs started to accumulate.

In the third phase of the MV-induced oxidative stress, about $40 \%$ of the soluble pool of PPs found in methanolic extracts of sunflower leaf discs was oxidized. This oxidation was characterized by a concomitant decrease of the absorbance that was maximal near $328 \mathrm{~nm}$, and a large increase of absorbance near $420 \mathrm{~nm}$, changes that are typical of phenolic oxidation (Ramešová et al. 2015; Sokolová et al. 2012). Specifically, the maximum near $328 \mathrm{~nm}$ is characteristic for hydroxycinnamic acids and their ester chlorogenic acid, which are the dominant type of PPs in sunflower leaves (Stelzner et al. 2019). The estimations of polyphenol oxidation by A328 decrease were corroborated by their close correlation with the reducing PPs contents estimated by the Folin-Ciocalteu method.

Cyclic voltammetry is frequently used to estimate the antioxidant capacity of plant extracts (Neill et al. 2002) and beverages such as wines and teas (Kilmartin and Hsu 2003; Kilmartin et al. 2001), but has not been used yet to characterise PPs in leaf extracts in a physiological context related to photosynthesis and photooxidative stress. Here, we used this method to obtain a descriptive illustration of the loss of reducing PPs in methanolic extracts from MV-treated leaf discs. Compared to the control leaf discs, the main effect of the MV-treatment is the loss of the oxidative wave near $240 \mathrm{mV}$. Different phenolic compounds such as gallic acid, caffeic acid, quercetin, and catechin show similar voltammograms, with the same main oxidation wave near $240 \mathrm{mV}$ measured at $\mathrm{pH} 7.0$ (Hernanz-Vila et al. 2017). Voltammograms from green and black teas also show a main oxidation wave near $230 \mathrm{mV}(\mathrm{pH}$ 7.0), which was lower for the black tea, consistent with the oxidation of black tea leaves (Kilmartin and Hsu 2003; Sava et al. 2001). 
The presence of oxidized PPs was detected by the absorbance increase near $420 \mathrm{~nm}$ in methanolic extracts of leaf discs treated with for four to eight hours (Fig. 3a). However, most of the oxidized PPs may have polymerized in situ or react with proteins to form insoluble brown pigments, or melanin-brown pigments (Pourcel et al. 2007; Takahama 2004; Yamasaki et al. 1997). Their presence affected leaf optical properties, notably by decreased reflectance in the green and far-red regions, less dominated by chlorophylls. The decrease was significant after 6 hours of treatment, i.e. two hours later than the absorbance increase at $420 \mathrm{~nm}$ in the methanolic extracts was detected. This suggests that concentration of oxidized PPs must reach some level to initiate their polymerization leading to the accumulation of brown pigments in significant amount to affect leaf reflectance. The presence of insoluble brown pigments in MV-treated leaves was confirmed by measuring reflectance spectra of depigmented leaf discs after incubation in methanol: the reflectance was much lower for MV-treated leaf discs than control leaf-discs.

Fluorescence spectroscopy provides a comprehensive view of the effects induced by the MV-treatment described above, i.e. the transient changes of the fluorescence levels Fs, the losses of PSII photochemical efficiencies, the accumulation of brown pigments, and the decrease of UVabsorbing compounds. Variations of the Fs levels are the results of two opposite effects. A closure of PSII reactions centers causes Fs to increase, whereas an opposite effect on Fs results from the presence of a non-photochemical quenching, either due to the presence of the lightinduced acidification of the thylakoid lumen (leading to the formation of zeaxanthin) or to the presence of damaged PSII (Klughammer and Schreiber 2008). So, the Fs increase seen at the fourth hour indicates a higher proportion of closed PSII, likely due to the loss of the regulated NPQ. This transient Fs increase is followed by Fs quenching below the initial values, indicating damages PSII at six and eight hours. This Fs pattern is evident in the averaged intensity of the chlorophyll- $a$ emission spectrum of fluorescence excited at $550 \mathrm{~nm}$ (Fig. 7), of the excitation spectrum of fluorescence emitted at $740 \mathrm{~nm}$ (Fig. 8), and also in the intensities of the far-red fluorescence induced by blue excitation measured by the Multiplex 330 portable fluorometer (Fig. 9a).

Besides the variations of the overall intensity of the fluorescence emission spectrum, it is interesting to note the preferential decrease of the $F^{740}$ relative to $F^{684}$, so the $F^{740} / F^{684}$ ratio decreased closely to Fv/Fm $\left(\mathrm{R}^{2}=0.981\right)$ during the MV-treatment. This correlation does not indicate a causal relation between the two variables. Indeed, specific inhibition of PSII due to photoinhibition or other stress (heat, chilling...) decreases preferentially the $\mathrm{F}^{684}$ band (Agati et al. 1995). Thereby, the $\mathrm{F}^{740} / \mathrm{F}^{684}$ ratio should increase during the MV-treatment rather than decrease. However, the chlorophyll- $a$ fluorescence emission spectra from our sunflower leaf discs are characterized by a low $\mathrm{F}^{684}$ relative to $\mathrm{F}^{740}$ intensities. This is due to the large chlorophylls concentrations in sunflower leaves and the excitation at $550 \mathrm{~nm}$, two factors causing the preferential re-absorption of red fluorescence and then high $\mathrm{F}^{740} / \mathrm{F}^{684}$ (Agati et al. 1995; Agati et al. 1996; Buschmann and Lichtenthaler 1998; Gitelson et al. 1999). Here, the low $F^{684}$ intensity relative to $\mathrm{F}^{740}$ makes the $\mathrm{F}^{740} / \mathrm{F}^{684}$ less sensitive to lower PSII quantum yield. The observed correlation $\mathrm{F}^{740} / \mathrm{F}^{684}$ and $\mathrm{Fv} / \mathrm{Fm}$ rather indicates that both variables are similarly affected by a common factor, here the oxidative stress, causing the decrease of $\mathrm{Fv} / \mathrm{Fm}$, and the accumulation of brown pigments. The stronger decrease of reflectance at $740 \mathrm{~nm}$ than at $684 \mathrm{~nm}$ seen in MV- 
treated leaf discs (see Fig. 5a) would cause preferential absorption of $\mathrm{F}^{740}$, and therefore the decrease of the $\mathrm{F}^{740} / \mathrm{F}^{684}$ ratio.

Complementary information about the MV-induced oxidative damaged in sunflower leaf discs was provided by the excitation spectra of the chlorophyll- $a$ fluorescence emitted at $740 \mathrm{~nm}$ (the emission band not reabsorbed by chlorophyll). Besides the averaged fluorescence intensity that varied similarly to Fs (a transient increase at four hours before declining afterward), there is a specific decrease of the main fluorescence-excitation peak at $484 \mathrm{~nm}$ during the MV-treatment. Zeng et al. (2016) showed that illumination of isolated chloroplasts caused a preferential decrease of fluorescence excitation near $477 \mathrm{~nm}$, which was interpreted as a decrease of energy transfer between the antenna pigments, both chlorophyll- $b$ and carotenoids. In contrast, Nichelmann et al. (2016) observed that a strong illumination (1200 umoles $\mathrm{m}^{-2} \mathrm{~s}^{-1}$ for 15 minutes) barely decreased the fluorescence excitation ratio $\mathrm{F}_{470} / \mathrm{F}_{660}$ measured in Arabidopsis thaliana leaves. They rather demonstrated the presence of a good correlation between this $\mathrm{F}_{470} / \mathrm{F}_{660}$ ratio and the violaxanthin cycle pool size in $A$. thaliana leaves acclimated to different growth irradiances. Since during our experiment the total carotenoid contents remained constant, the similar decreases of $\mathrm{F}_{484} / \mathrm{F}_{680}$ and $\Delta \mathrm{F} / \mathrm{Fm}$ ' therefore indicates a loss of energy transfer between the antenna pigments and the reaction center of PSII caused by the MV-treatment. It will be interesting to determine the relative importance of energy transfer between the antenna pigments and xanthophylls pool size on the $\mathrm{F}_{484} / \mathrm{F}_{680}$ ratio in different species and conditions, as the chlorophyll- $a$ fluorescence intensities induced at these two excitation wavelengths could potentially provide an estimate of photosynthetic efficiency in proximal fluorosensing.

Concerning the second main excitation peak, at $422 \mathrm{~nm}$, its larger attenuation relative to the red part of the spectrum can be attributed to the accumulation of brown pigments, which absorb maximally at $420 \mathrm{~nm}$ (Takahama et al. 1999; see Fig. 3a).

In contrast of the decreases of averaged fluorescence intensities mentioned above, excitation spectra showed higher UV-excited chlorophyll- $a$ fluorescence intensities in MVtreated leaf discs compared to control discs. Intensities of UV-excited chlorophyll- $a$ fluorescence are naturally weak due to the lower absorbance of chlorophylls in that spectral region, and also due to the blocking of UV-excitation by the presence of hydroxycinnamates in the epidermis of sunflower leaves (Cerovic et al. 2002; Stelzner et al. 2019). These increases of UV-excited fluorescence in MV-treated leaf discs are coherent with the oxidation of PPs seen by the decrease of UV-absorbance of the methanolic leaf extracts. They are also well supported by the measurements made with the portable fluorometer Multiplex 330. Whereas blue-excited far-red fluorescence followed the same patterns as Fs, UV-excited $(330 \mathrm{mn})$ far-red fluorescence markedly increased after four hours of MV-treatment. This corresponds to a 53\% decrease of LogFER, that estimates leaf epidermal UV-absorbance, coherent with the loss of UV-absorbing compounds with an absorbance maximum near $328 \mathrm{~nm}$ (Fig. 3b).

Globally, our study provide one of the missing evidences required to confirm that PPs act as effective antioxidants protecting the plants against ROS, by showing the presence of a temporal correlation between the inhibition of $\mathrm{Fv} / \mathrm{Fm}$ and the oxidation of PPs during an acute oxidative stress in sunflower leaf discs. We showed that fluorescence and reflectance 
spectroscopy as well as cyclic voltammetry could be useful in future studies to test the hypothesis that leaves with higher PPs contents, Fv/Fm could either persists longer or declines slower during acute oxidative stress.

Acknowledgements We are grateful to Lionel Saunois and Amandine Dubois from the greenhouse facility for taking care of the sunflower plants, and to Gwendal Latouche for his technical assistance. GS acknowledges his sabbatical leave from the Université du Québec à Trois-Rivières.

\section{Compliance with ethical standards}

Conflict of interest ZGC declares a link to the company FORCE-A as one of the co-authors of the Multiplex patent that the company exploits. Other authors have no competing interests.

\section{References}

Agati G, Azzarello E, Pollastri S, Tattini M (2012) Flavonoids as antioxidants in plants: Location and functional significance. Plant Sci 196:67-76. doi:10.1016/j.plantsci.2012.07.014

Agati G, Matteini P, Goti A, Tattini M (2007) Chloroplast-located flavonoids can scavenge singlet oxygen. New Phytol 174 (1):77-89. doi:10.1111/j.1469-8137.2007.01986.x

Agati G, Mazzinghi P, Fusi F, Ambrosini I (1995) The F685/F730 Chlorophyll Fluorescence Ratio as a Tool in Plant Physiology: Response to Physiological and Environmental Factors. J PLANT PHYSIOL 145 (3):228-238. doi:10.1016/S0176-1617(11)81882-1

Agati G, Mazzinghi P, Lipucci Di Paola M, Fusi F, Cecchi G (1996) The F685/F730 chlorophyll fluorescence ratio as indicator of chilling stress in plants. J PLANT PHYSIOL 148 (34):384-390. doi:10.1016/S0176-1617(96)80270-7

Bertolini A, Petrussa E, Patui S, Zancani M, Peresson C, Casolo V, Vianello A, Braidot E (2016) Flavonoids and darkness lower PCD in senescing Vitis vinifera suspension cell cultures. BMC Plant Biol 16 (1). doi:10.1186/s12870-016-0917-y

Buschmann C, Lichtenthaler HK (1998) Principles and characteristics of multi-colour fluorescence imaging of plants. J PLANT PHYSIOL 152 (2-3):297-314. doi:10.1016/S01761617(98)80144-2

Cerovic ZG, Ounis A, Cartelat A, Latouche G, Goulas Y, Meyer S, Moya I (2002) The use of chlorophyll fluorescence excitation spectra for the non-destructive in situ assessment of UV-absorbing compounds in leaves. Plant Cell Environ 25 (12):1663-1676. doi:10.1046/j.1365-3040.2002.00942.x

Dixon RA, Paiva NL (1995) Stress-induced phenylpropanoid metabolism. PLANT CELL 7 (7):10851097. doi:10.1105/tpc.7.7.1085

Dong J, Wan G, Liang Z (2010) Accumulation of salicylic acid-induced phenolic compounds and raised activities of secondary metabolic and antioxidative enzymes in Salvia miltiorrhiza cell culture. J Biotechnol 148 (2-3):99-104. doi:10.1016/j.jbiotec.2010.05.009

Edreva A (2005) The importance of non-photosynthetic pigments and cinnamic acid derivatives in photoprotection. Agric Ecosyst Environ 106 (2-3 SPEC. ISS.):135-146. doi:10.1016/j.agee.2004.10.002 
Ghasemzadeh A, Ghasemzadeh N (2011) Flavonoids and phenolic acids: Role and biochemical activity in plants and human. J Med Plant Res 5 (31):6697-6703. doi:10.5897/JMPR11.1404

Gitelson AA, Buschmann C, Lichtenthaler HK (1999) The chlorophyll fluorescence ratio F735F700 as an accurate measure of the chlorophyll content in plants. Remote Sens Environ 69 (3):296-302. doi:10.1016/S0034-4257(99)00023-1

Hayat Q, Hayat S, Irfan M, Ahmad A (2010) Effect of exogenous salicylic acid under changing environment: A review. Environ Exp Bot 68 (1):14-25. doi:10.1016/j.envexpbot.2009.08.005

Hernández I, Alegre L, Munné-Bosch S (2006) Enhanced oxidation of flavan-3-ols and proanthocyanidin accumulation in water-stressed tea plants. Phytochemistry 67 (11):1120-1126. doi:10.1016/j.phytochem.2006.04.002

Hernández I, Alegre L, Van Breusegem F, Munné-Bosch S (2009) How relevant are flavonoids as antioxidants in plants? Trends Plant Sci 14 (3):125-132. doi:10.1016/j.tplants.2008.12.003

Hernanz-Vila D, Jara-Palacios MJ, Escudero-Gilete ML, Heredia FJ (2017) Applications of Voltammetric Analysis to Wine Products. In: Stoytcheva M, Zlatev R (eds) Applications of the Voltammetry. IntechOpen Limited, London, U.K., pp 109-127. doi:http://dx.doi.org/10.5772/67696

Jaiswal S, Chawla R, Sawhney S (2012) Correlations among attributes of senescence and antioxidative status of leaf discs during epiphyllous bud differentiation in Kalanchoe pinnata Lam. (Pers.). Z Naturforsch Sect C J Biosci 67 C (7-8):418-428. doi:10.1515/znc2012-7-810

Kilmartin PA, Hsu CF (2003) Characterisation of polyphenols in green, oolong, and black teas, and in coffee, using cyclic voltammetry. Food Chem 82 (4):501-512. doi:10.1016/S03088146(03)00066-9

Kilmartin PA, Zou H, Waterhouse AL (2001) A cyclic voltammetry method suitable for characterizing antioxidant properties of wine and wine phenolics. J Agric Food Chem 49 (4):1957-1965. doi:10.1021/jf001044u

Klughammer C, Schreiber U (2008) Complementary PS II quantum yields calculated from simple fluorescence parameters measured by PAM fluorometry and the Saturation Pulse method. PAM Application Notes 1:27-35

Kováčik J, Grúz J, Bačkor M, Strnad M, Repčák M (2009) Salicylic acid-induced changes to growth and phenolic metabolism in Matricaria chamomilla plants. Plant Cell Rep 28 (1):135-143. doi:10.1007/s00299-008-0627-5

Kováčik J, Klejdus B, Hedbavny J, Bačkor M (2010) Effect of copper and salicylic acid on phenolic metabolites and free amino acids in Scenedesmus quadricauda (Chlorophyceae). Plant Sci 178 (3):307-311. doi:10.1016/j.plantsci.2010.01.009

Lichtenthaler HK (1987) Chlorophylls and Carotenoids: Pigments of Photosynthetic Biomembranes. Methods in Enzymology, vol 148. doi:10.1016/0076-6879(87)48036-1

Louis J, Genet H, Meyer S, Soudani K, Montpied P, Legout A, Dreyer E, Cerovic ZG, Dufr̂ne E (2012) Tree age-related effects on sun acclimated leaves in a chronosequence of beech (Fagus sy/vatica) stands. Funct Plant Biol 39 (4):323-331. doi:10.1071/FP11248

Louis J, Meyer S, Maunoury-Danger F, Fresneau C, Meudec E, Cerovic ZG (2009) Seasonal changes in optically assessed epidermal phenolic compounds and chlorophyll contents in leaves of sessile oak (Quercus petraea): Towards signatures of phenological stage. Funct Plant Biol 36 (8):732-741. doi:10.1071/FP09010 
Mandal SM, Chakraborty D, Dey S (2010) Phenolic acids act as signaling molecules in plantmicrobe symbioses. Plant Signal Behav 5 (4):359-368. doi:10.4161/psb.5.4.10871

Meir S, Kanner J, Akiri B, Philosoph-Hadas S (1995) Determination and Involvement of Aqueous Reducing Compounds in Oxidative Defense Systems of Various Senescing Leaves. J Agric Food Chem 43 (7):1813-1819. doi:10.1021/jf00055a012

Nakabayashi R, Saito K (2015) Integrated metabolomics for abiotic stress responses in plants. Curr Opin Plant Biol 24:10-16. doi:10.1016/j.pbi.2015.01.003

Nakabayashi R, Yonekura-Sakakibara K, Urano K, Suzuki M, Yamada Y, Nishizawa T, Matsuda F, Kojima M, Sakakibara H, Shinozaki K, Michael AJ, Tohge T, Yamazaki M, Saito K (2014) Enhancement of oxidative and drought tolerance in Arabidopsis by overaccumulation of antioxidant flavonoids. Plant J 77 (3):367-379. doi:10.1111/tpj.12388

Neill SO, Gould KS, Kilmartin PA, Mitchell KA, Markham KR (2002) Antioxidant capacities of green and cyanic leaves in the sun species, Quintinia serrata. Funct Plant Biol 29 (12):1437-1443. doi:10.1071/FP02100

Nichelmann L, Schulze M, Herppich WB, Bilger W (2016) A simple indicator for non-destructive estimation of the violaxanthin cycle pigment content in leaves. Photosynth Res 128 (2):183-193. doi:10.1007/s11120-016-0218-1

Pérez FJ, Villegas D, Mejia N (2002) Ascorbic acid and flavonoid-peroxidase reaction as a detoxifying system of $\mathrm{H}_{2} \mathrm{O}_{2}$ in grapevine leaves. Phytochemistry 60 (6):573-580. doi:10.1016/S0031-9422(02)00146-2

Pourcel L, Routaboul JM, Cheynier V, Lepiniec L, Debeaujon I (2007) Flavonoid oxidation in plants: from biochemical properties to physiological functions. Trends Plant Sci 12 (1):29-36. doi:10.1016/j.tplants.2006.11.006

Prior RL, Wu X, Schaich K (2005) Standardized methods for the determination of antioxidant capacity and phenolics in foods and dietary supplements. J Agric Food Chem 53 (10):4290-4302. doi:10.1021/jf0502698

Ramešová Š, Sokolová R, Degano I (2015) The study of the oxidation of the natural flavonol fisetin confirmed quercetin oxidation mechanism. Electrochim Acta 182:544-549. doi:10.1016/j.electacta.2015.09.144

Sava VM, Galkin BN, Hong MY, Yang PC, Huang GS (2001) A novel melanin-like pigment derived from black tea leaves with immuno-stimulating activity. Food Res Int 34 (4):337-343. doi:10.1016/S0963-9969(00)00173-3

Shao L, Shu Z, Peng CL, Lin ZF, Yang CW, Gu Q (2008) Enhanced sensitivity of Arabidopsis anthocyanin mutants to photooxidation: A study with fluorescence imaging. Funct Plant Biol 35 (8):714-724. doi:10.1071/FP08069

Sokolová R, Ramešová S, Degano I, Hromadová M, Gál M, Abka J (2012) The oxidation of natural flavonoid quercetin. Chem Commun 48 (28):3433-3435. doi:10.1039/c2cc18018a

Stelzner J, Roemhild R, Garibay-Hernández A, Harbaum-Piayda B, Mock HP, Bilger W (2019) Hydroxycinnamic acids in sunflower leaves serve as UV-A screening pigments. Photochem Photobiol Sci 18 (7):1649-1659. doi:10.1039/c8pp00440d

Takahama U (2004) Oxidation of vacuolar and apoplastic phenolic substrates by peroxidase: Physiological significance of the oxidation reactions. Phytochem Rev 3 (1-2):207-219. doi:10.1023/B:PHYT.0000047805.08470.e3

Takahama U, Hirotsu M, Oniki T (1999) Age-dependent changes in levels of ascorbic acid and chlorogenic acid, and activities of peroxidase and superoxide dismutase in the apoplast of tobacco leaves: Mechanism of the oxidation of chlorogenic acid in the apoplast. Plant Cell Physiol 40 (7):716-724. doi:10.1093/oxfordjournals.pcp.a029598 
677
Tomás-Barberán FA, Gil MI, Castañer M, Artés F, Saltveit ME (1997) Effect of Selected Browning Inhibitors on Phenolic Metabolism in Stem Tissue of Harvested Lettuce. J Agric Food Chem 45 (3):583-589. doi:10.1021/jf960478f

Treutter D (2005) Significance of flavonoids in plant resistance and enhancement of their biosynthesis. Plant Biol 7 (6):581-591. doi:10.1055/s-2005-873009

Yamasaki H, Sakihama Y, Ikehara N (1997) Flavonoid-peroxidase reaction as a detoxification mechanism of plant cells against $\mathrm{H}_{2} \mathrm{O}_{2}$. Plant Physiology 115 (4):1405-1412. doi:10.1104/pp.115.4.1405

Zeng L, Wang Y, Zhou J (2016) Spectral analysis on origination of the bands at $437 \mathrm{~nm}$ and 475.5 $\mathrm{nm}$ of chlorophyll fluorescence excitation spectrum in Arabidopsis chloroplasts. Lumin 31 (3):769-774. doi:10.1002/bio.3022 


\section{$678 \quad$ Figure legends}

679

680

681

682

683

684

685

686

687

688

689

690

691

692

693

694

695

696

697

698

699

700

701

702

703

704

705

706

707

708

709

710

711

712

713

714

715

Fig. 1 Time course of the photooxidative damage to the photosynthetic electron transport in sunflower leaf discs monitored by the inhibition of the effective $\Delta \mathrm{F} / \mathrm{Fm}$ ' (a) and maximum (Fv/Fm) (b) quantum yields of photosystem II, and the changes of the maximum Fm' (c) and the stationary Fs (d) fluorescence levels. Leaf discs were exposed to $150 \mu$ moles photons $\mathrm{m}^{-2} \mathrm{~s}^{-1}$ in absence $(\circ)$ or in presence of $0.4 \mathrm{mM}$ methyl viologen $(\bullet)$.

Fig. 2 Concentrations of the chlorophyll $a+b$ and carotenoids in sunflower leaf discs during exposure to $150 \mu$ moles photons $\mathrm{m}^{-2} \mathrm{~s}^{-1}$ in absence $(\circ)$ or in presence of $0.4 \mathrm{mM}$ methyl viologen $(\bullet)$.

Fig. 3 Polyphenol oxidation estimated from leaf methanolic extracts. a) Chlorophyll-less absorbance spectra of extracts from leaf treated or not with methyl viologen for different times. b) Absorbance values at $328 \mathrm{~nm}$ of the methanolic extracts from control (०) and MV-treated (•) leaf discs, c) Concentrations of reducing polyphenols in the methanolic extracts by the Folin-Ciocalteu method, expressed in gallic acid equivalents.

Fig. 4 Cyclic voltammograms of methanolic extracts from leaf discs exposed to $150 \mu$ moles photons $\mathrm{m}^{-2} \mathrm{~s}^{-1}$ in absence or in presence of $0.4 \mathrm{mM}$ methyl viologen during 8 hours. Voltammograms were measured with a $3 \mathrm{~mm}$ glassy carbon electrode at $50 \mathrm{mV} \mathrm{s}^{-1}$ in $\mathrm{pH}$ 7.4 in a phosphate buffer.

Fig. 5 a) Reflectance spectra of sunflower leaf discs treated or not with methyl viologen for different times. b) Reflectance values at $740 \mathrm{~nm}$ of control (०) and methyl viologen-treated $(\bullet)$ leaf discs,

Fig. 6 Reflectance spectra of depigmented sunflower leaf discs treated or not with methyl viologen for 8 hours. After the treatments, intact discs were incubated in methanol at $4^{\circ} \mathrm{C}$ for 24 hours.

Fig. 7 a) Emission spectra of chlorophyll fluorescence excited at $550 \mathrm{~nm}$ measured from leaf discs treated or not with methyl viologen for different times. b) Fluorescence intensities emitted at $740 \mathrm{~nm}$ and c) Ratio of fluorescence intensities emitted at 740 and $684 \mathrm{~nm}$ from control ( $\circ$ ) and methyl viologen-treated $(\bullet)$ leaf discs during the experiment.

Fig. 8 a) Excitation spectra of chlorophyll fluorescence emitted at $740 \mathrm{~nm}$ measured from leaf discs treated or not with methyl viologen for different times. b) Ratio of fluorescence intensities excited at 484 and $680 \mathrm{~nm}$ measured from control (०) and MV-treated (•) leaf discs during the experiment. c) Correlation between the $\mathrm{F}_{484} / \mathrm{F}_{680}$ excitation ratio and the quantum yield of photosystem II $\Delta \mathrm{F} / \mathrm{Fm}$ ' measured. d) Intensities of fluorescence at 740 $\mathrm{nm}$ excited at $350 \mathrm{~nm}$ during the 8-hour experiment in control (०) and methyl viologentreated $(\bullet)$ leaf discs.

Fig. 9 Blue-excited (a) and UV-excited (b) far-red fluorescence measured with a Multiplex portable fluorometer from control ( $($ ) and methyl viologen-treated $(\bullet)$ leaf discs during the 8-hour experiment. c) $\operatorname{LogFER}\left(\log \left(\mathrm{FRF}_{\mathrm{BLUE}} / \mathrm{FRF}_{\mathrm{UV}}\right)\right.$ as an estimation of the epidermal 
719

720 Fig. 1S Fig. 3 Polyphenol oxidation estimated from leaf methanolic extracts. Absorbance spectra 721

722 UV-absorbance of control (०) and methyl viologen-treated $(\bullet)$ leaf discs during the experiment. 


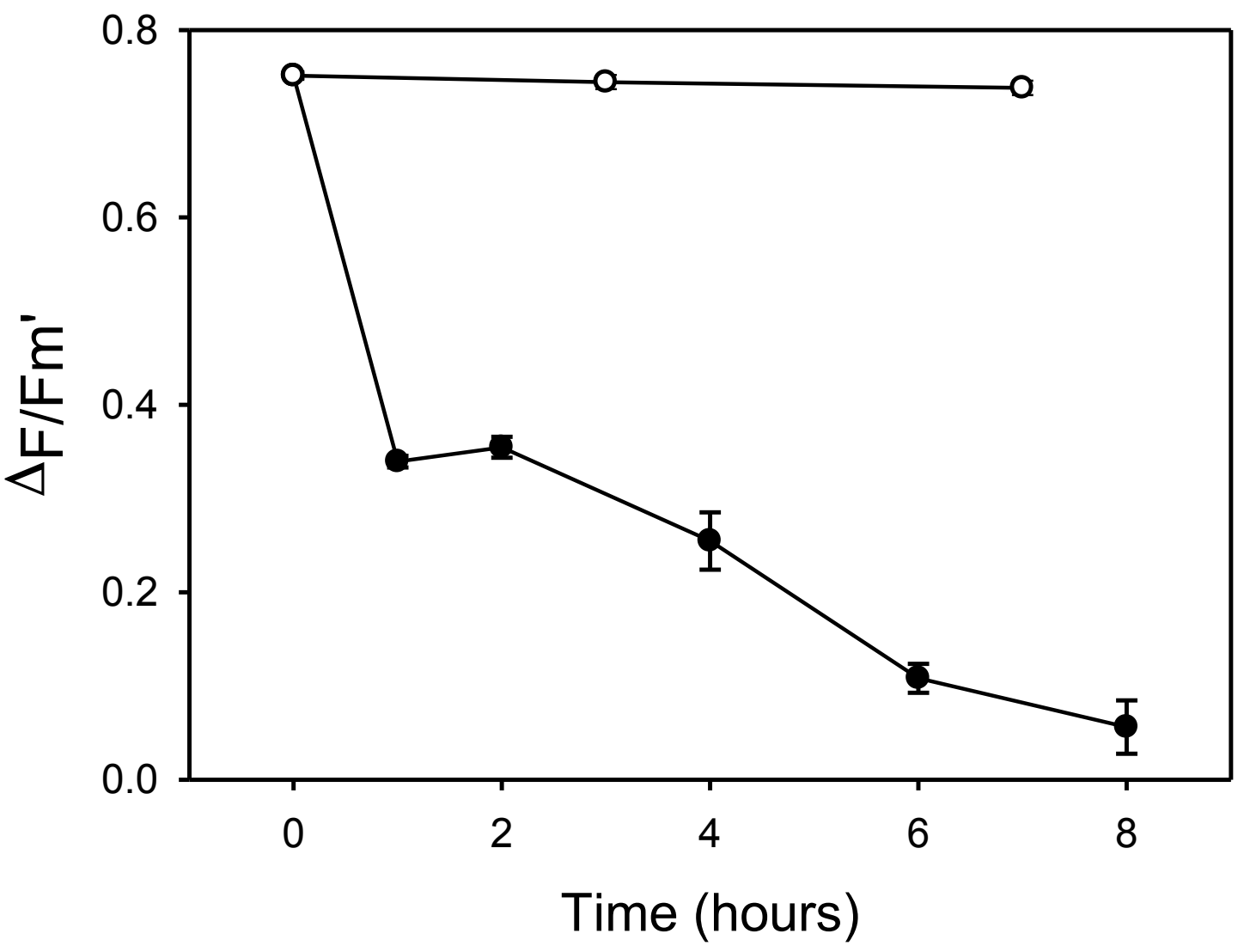

723

724

725

726

727

728

729

730

731

732

733

734 Figure 1a

735 


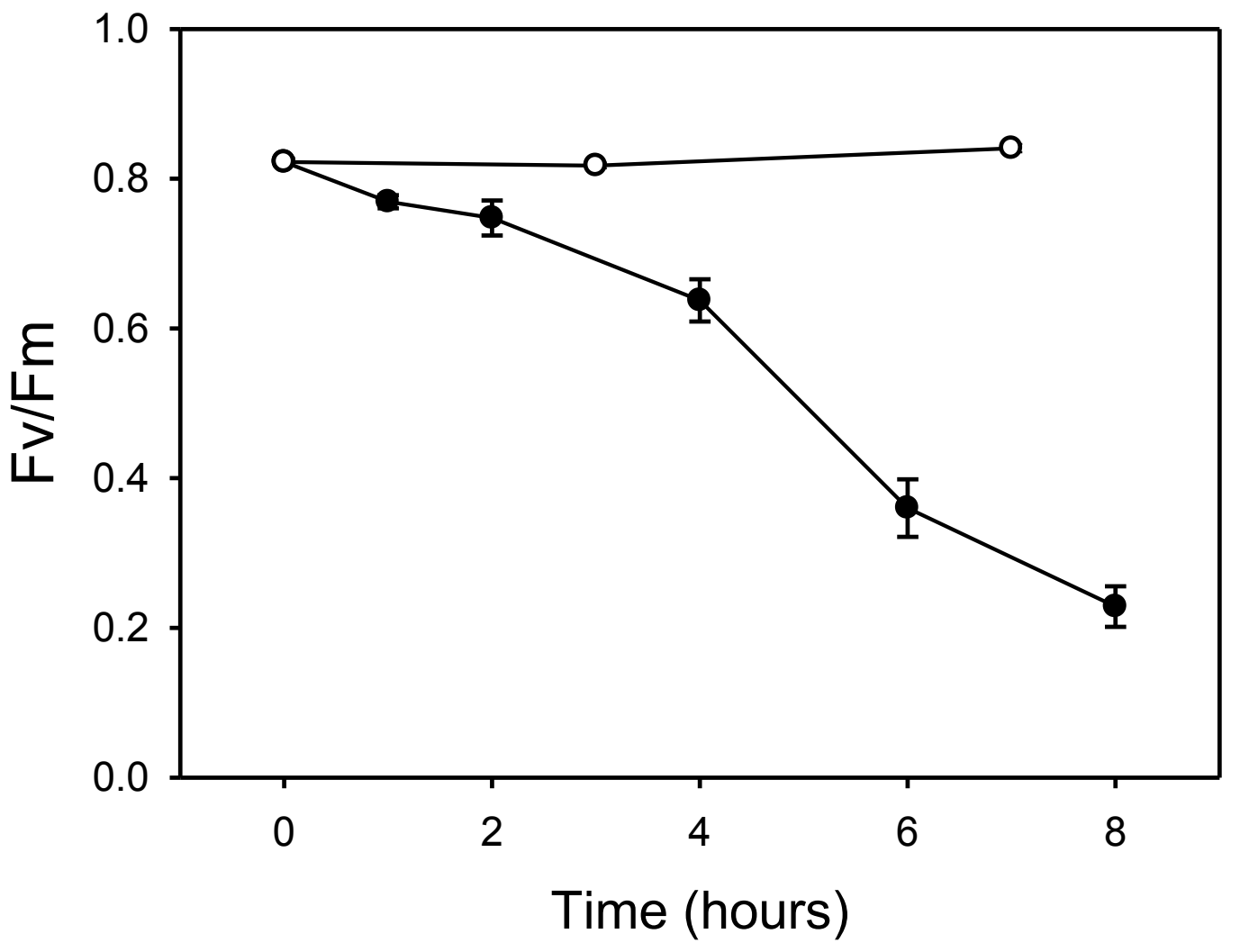

$746 \quad$ Figure $1 b$

747 


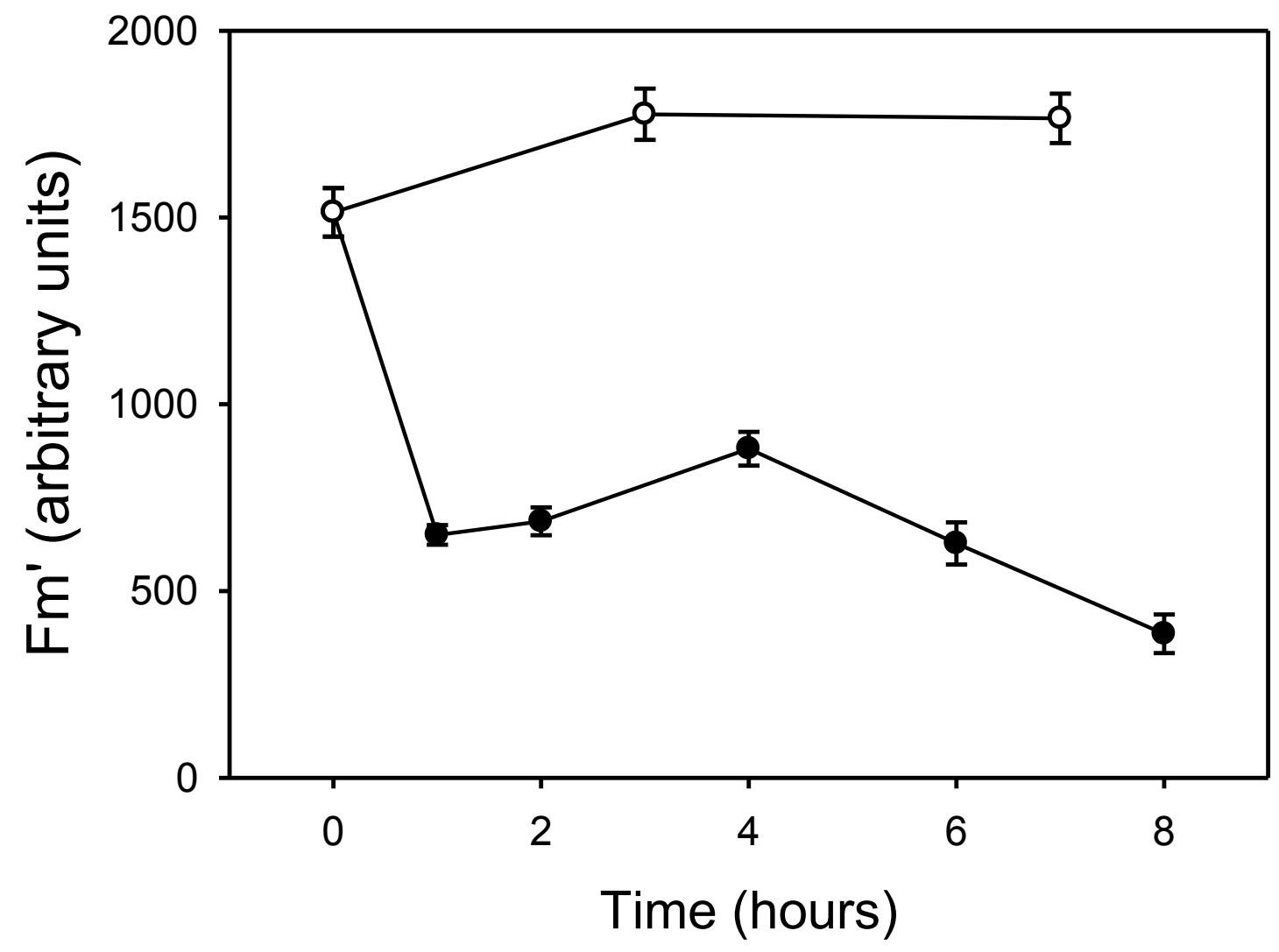

Figure 1c 


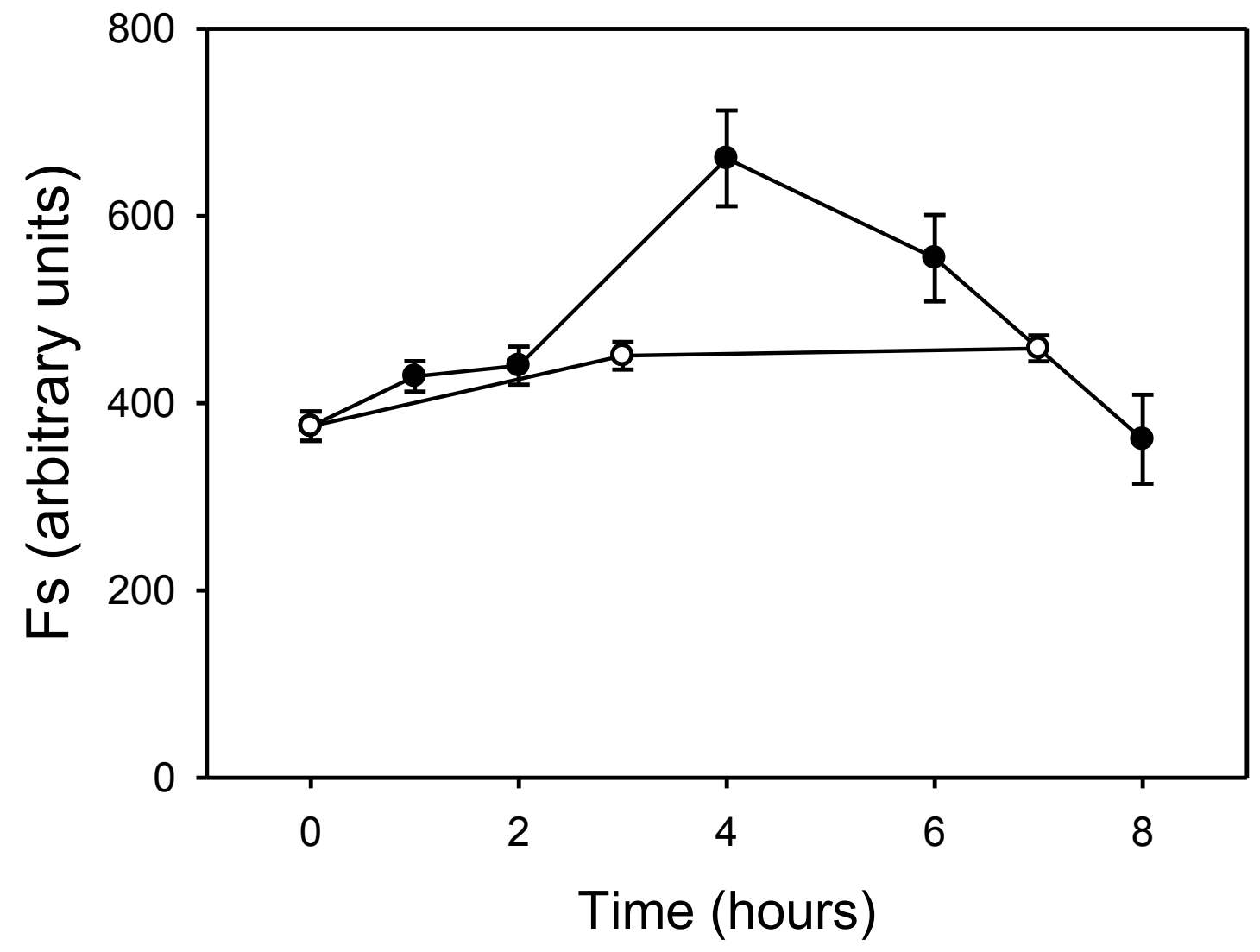

761

762

763

764

765

766

767

768

769

770

771

772 Figure $1 d$

773 


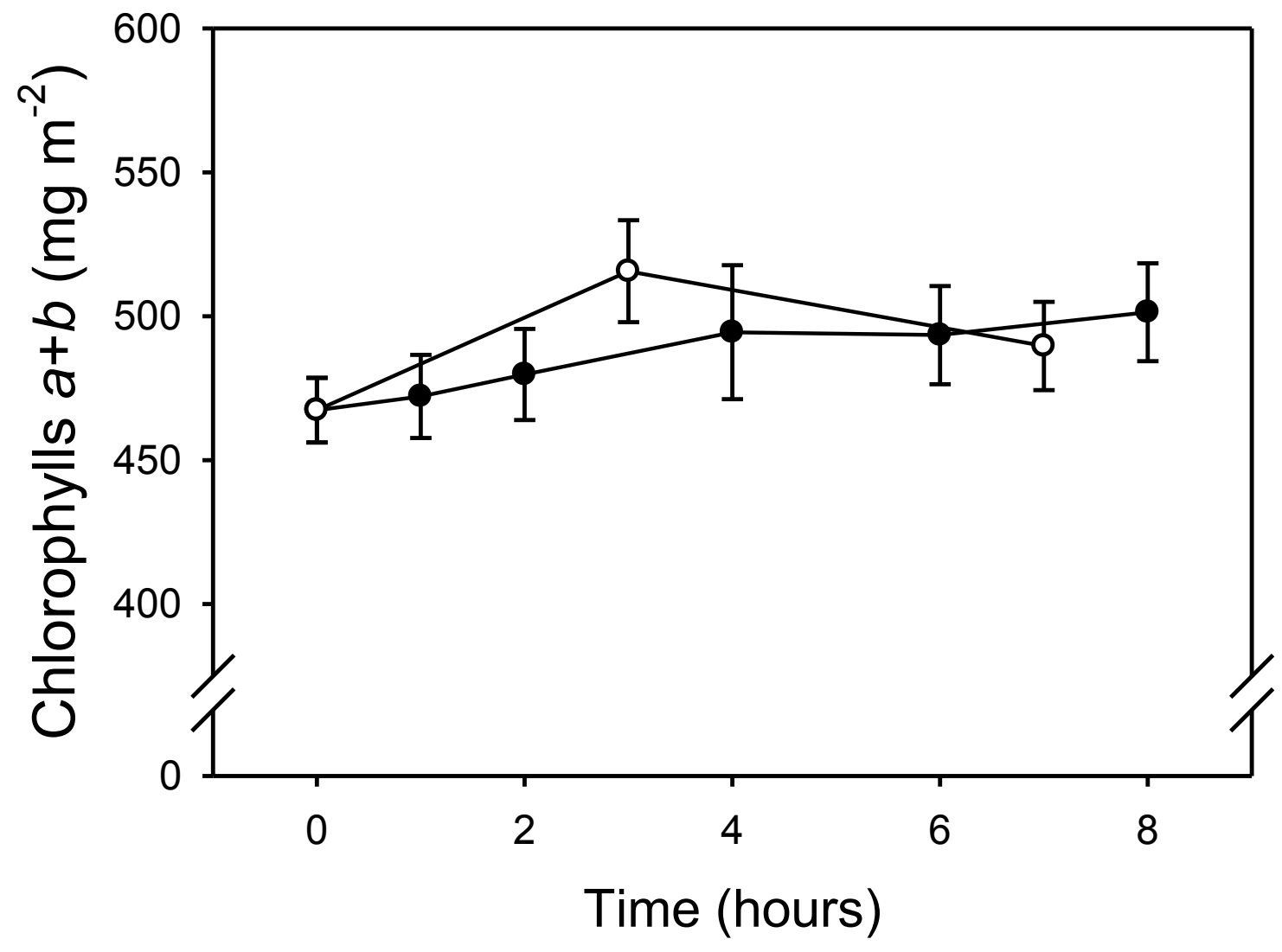

775
776

777

778

779

780

781

782

783

784

785

786

Figure $2 \mathrm{a}$

787 


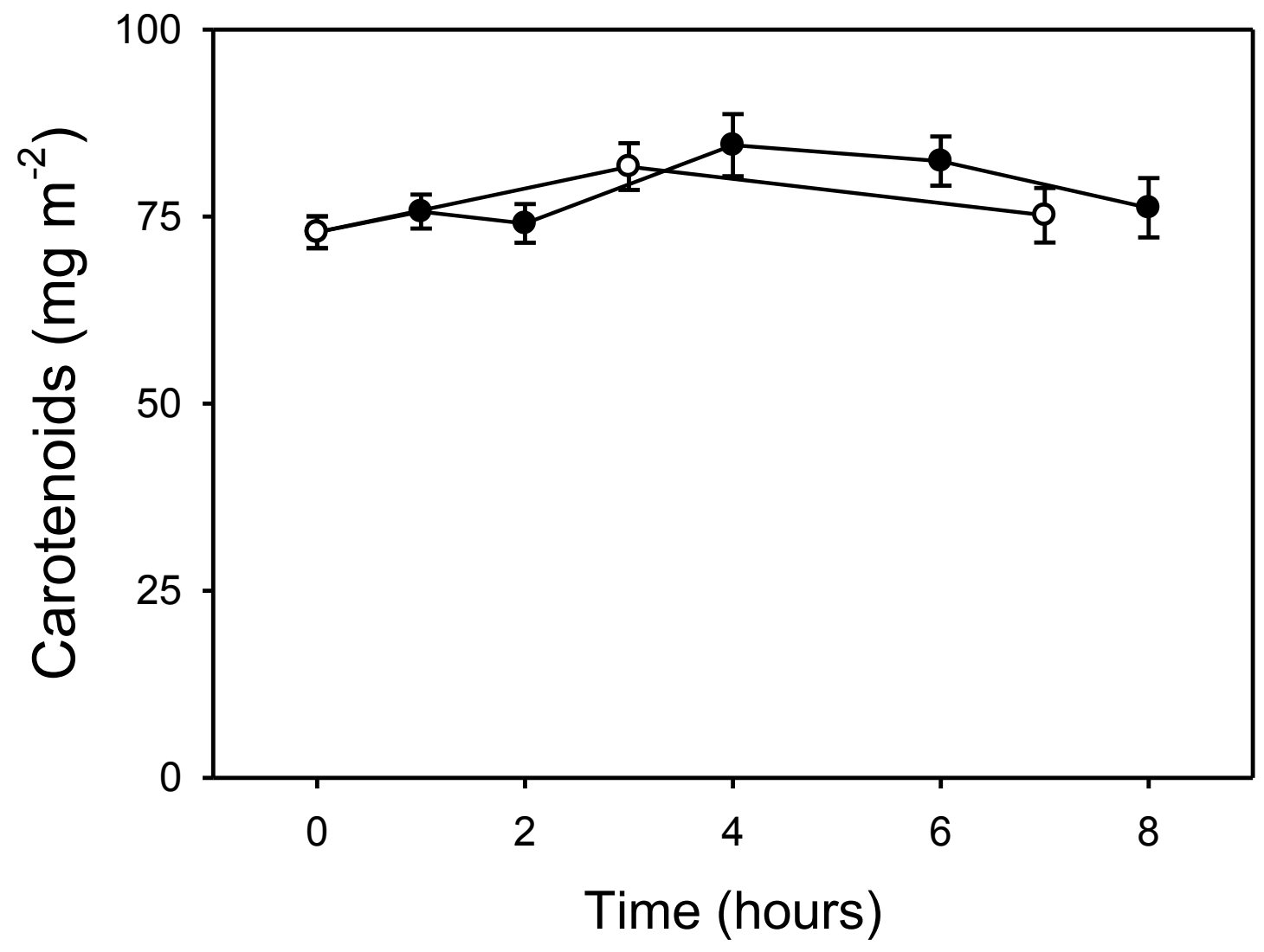

789

791

792

793

794

795

796

797

798

799

Figure $2 b$

800 


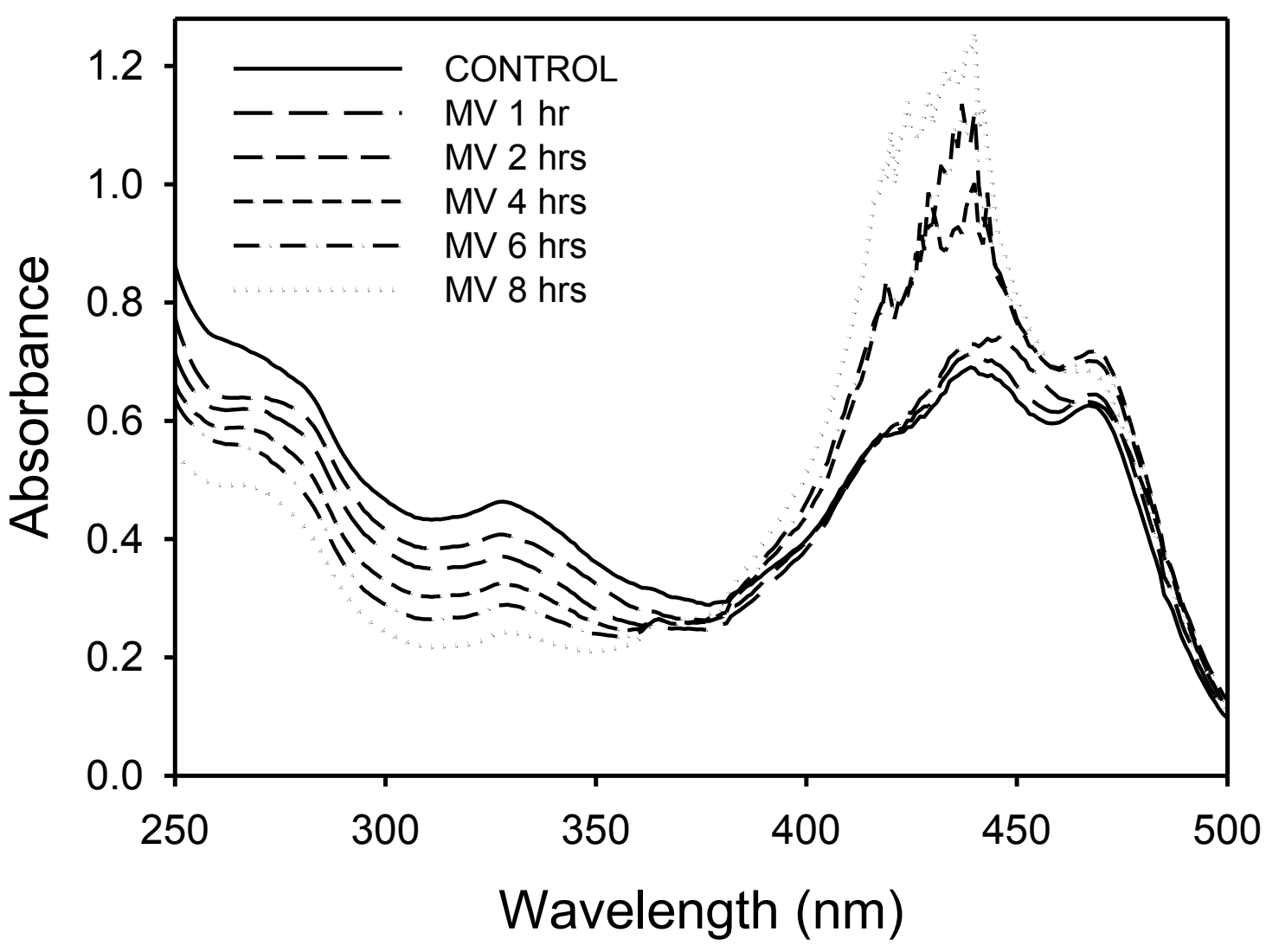

803

804 


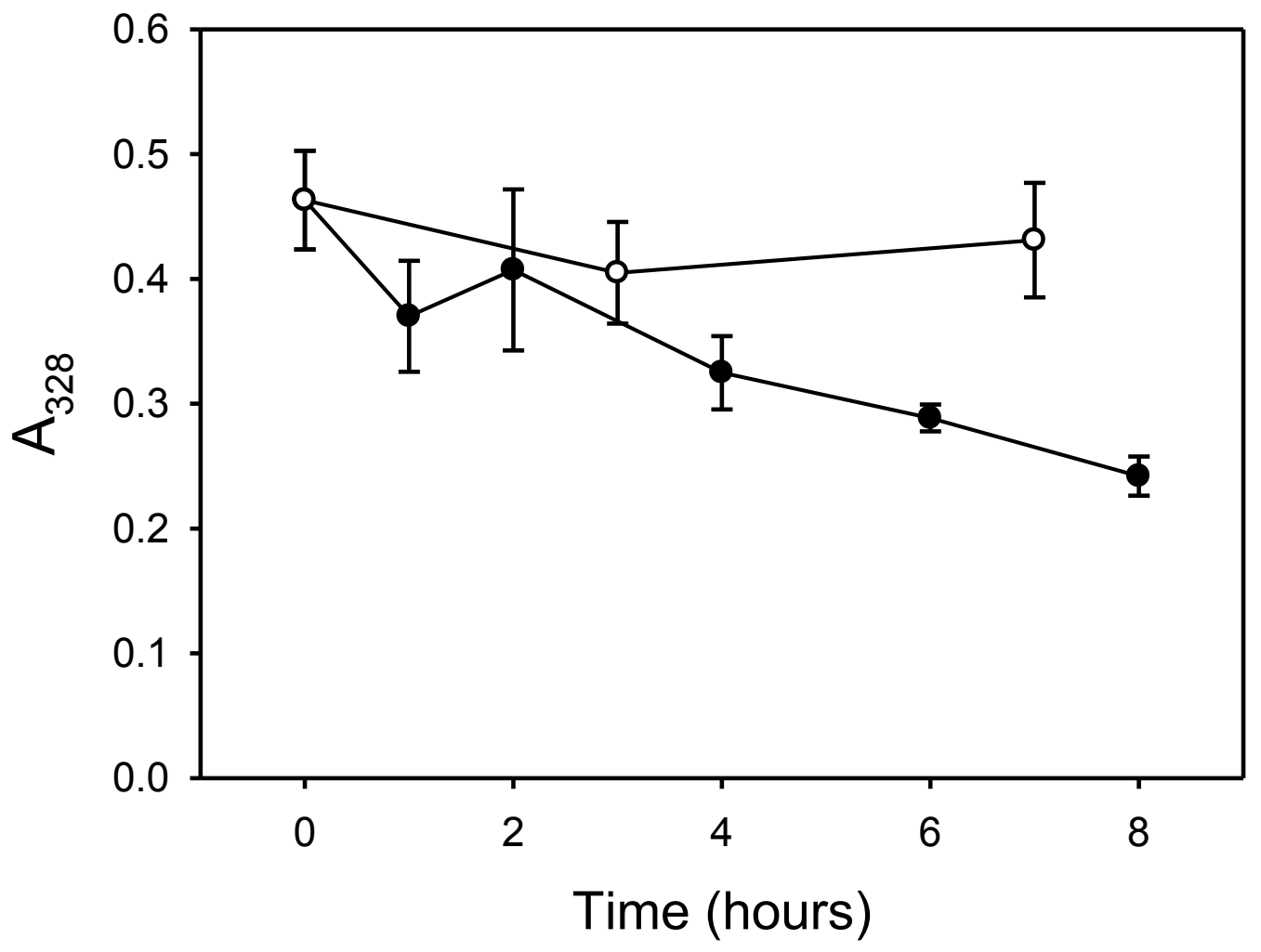

824 Figure $3 b$

825 


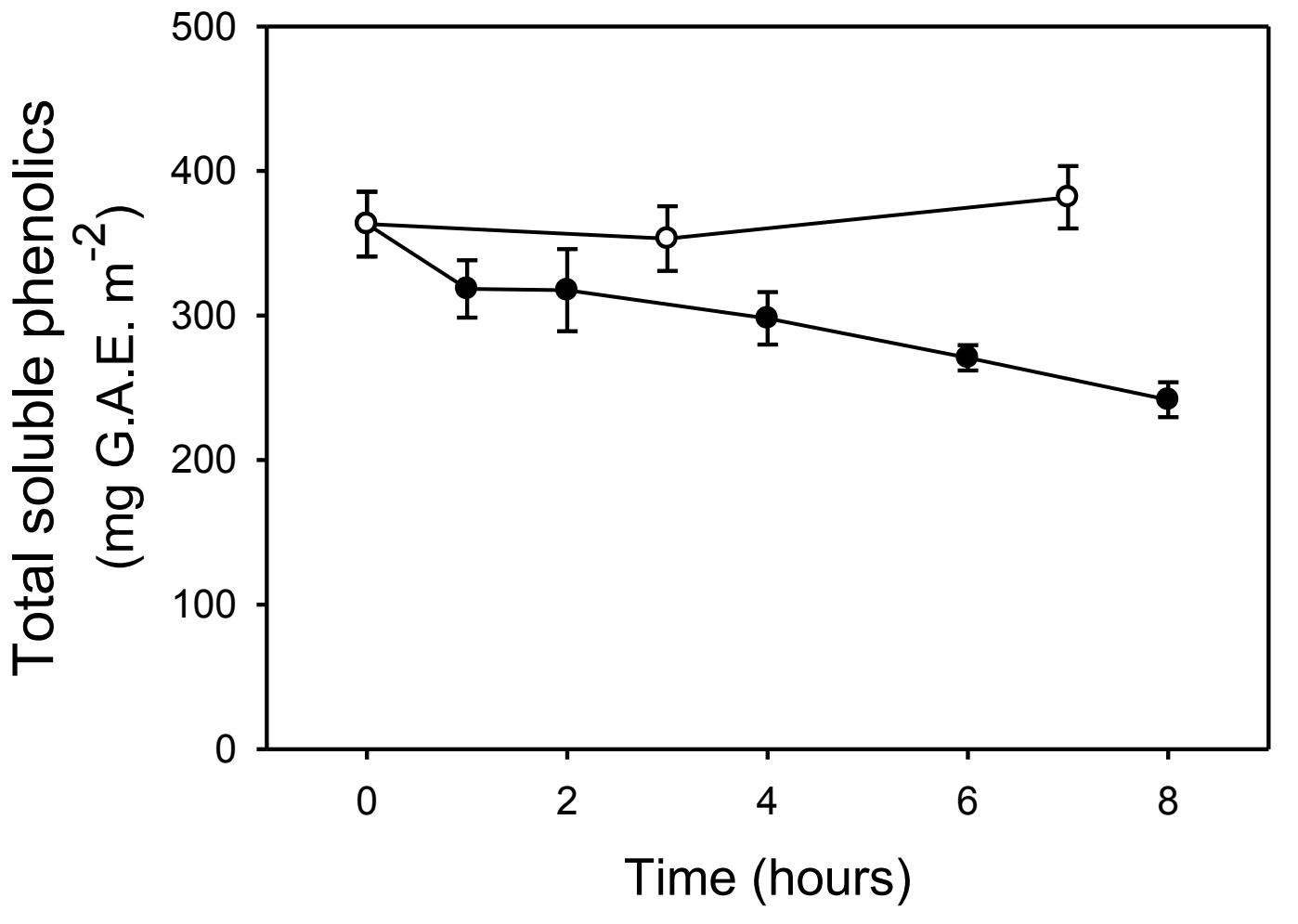

828

829

830

831

832

833

834

835

836

837

838 Figure $3 c$

839 


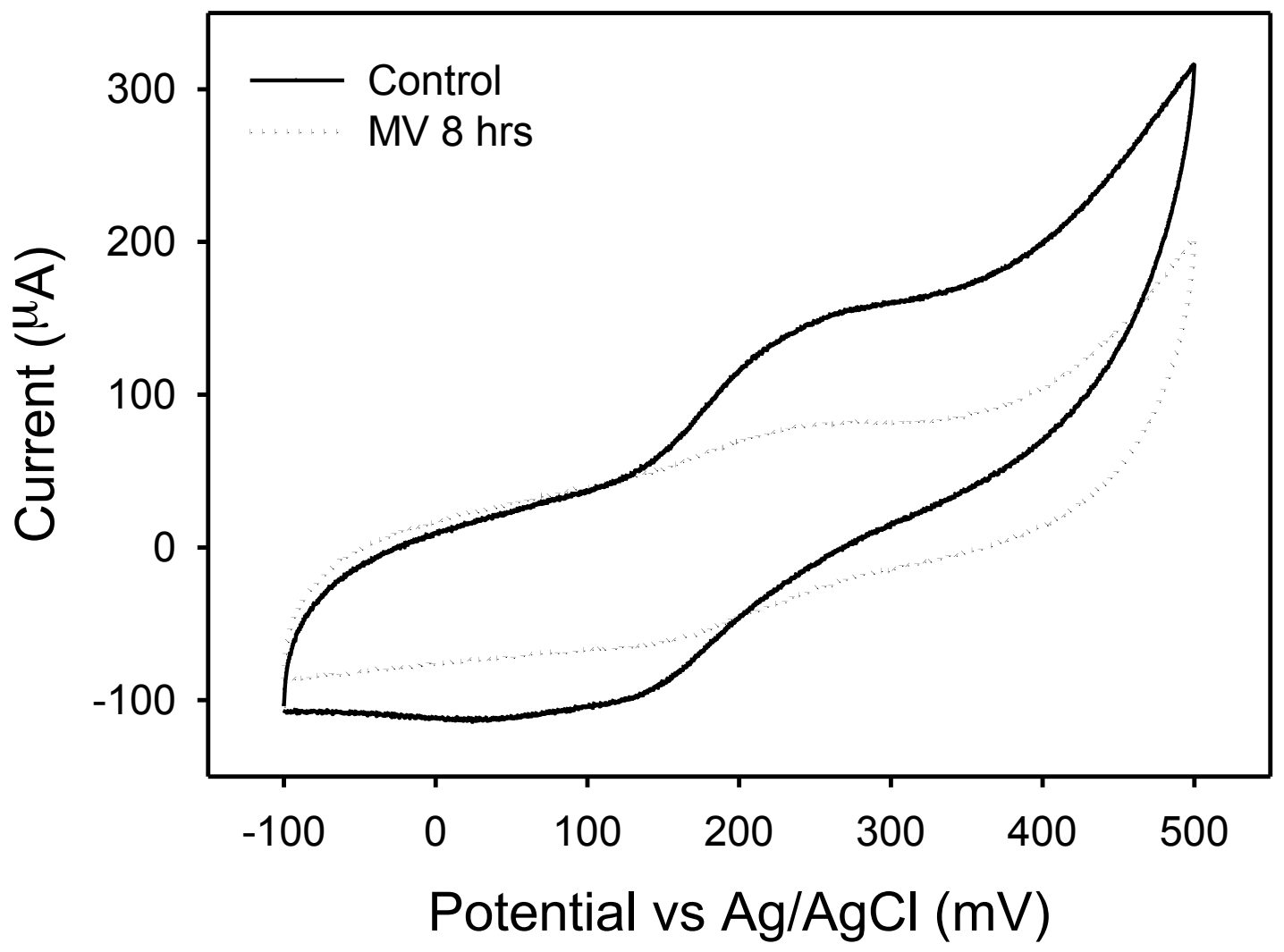

841
842

843

844

845

846

847

848

$849 \quad$ Fig. 4 


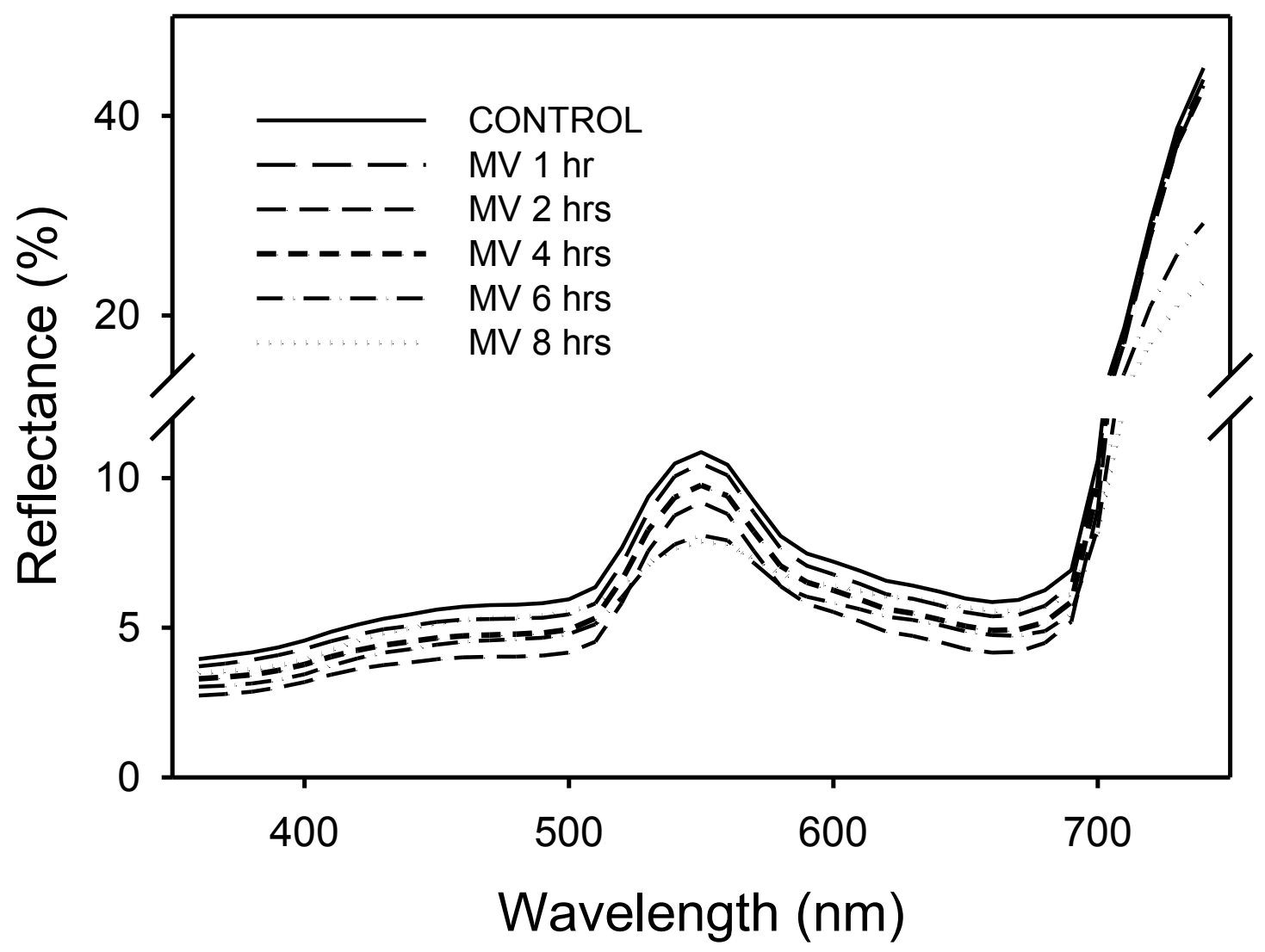

851

852

853

854

855

856

857

858

859

860

861 Figure 5a

862 


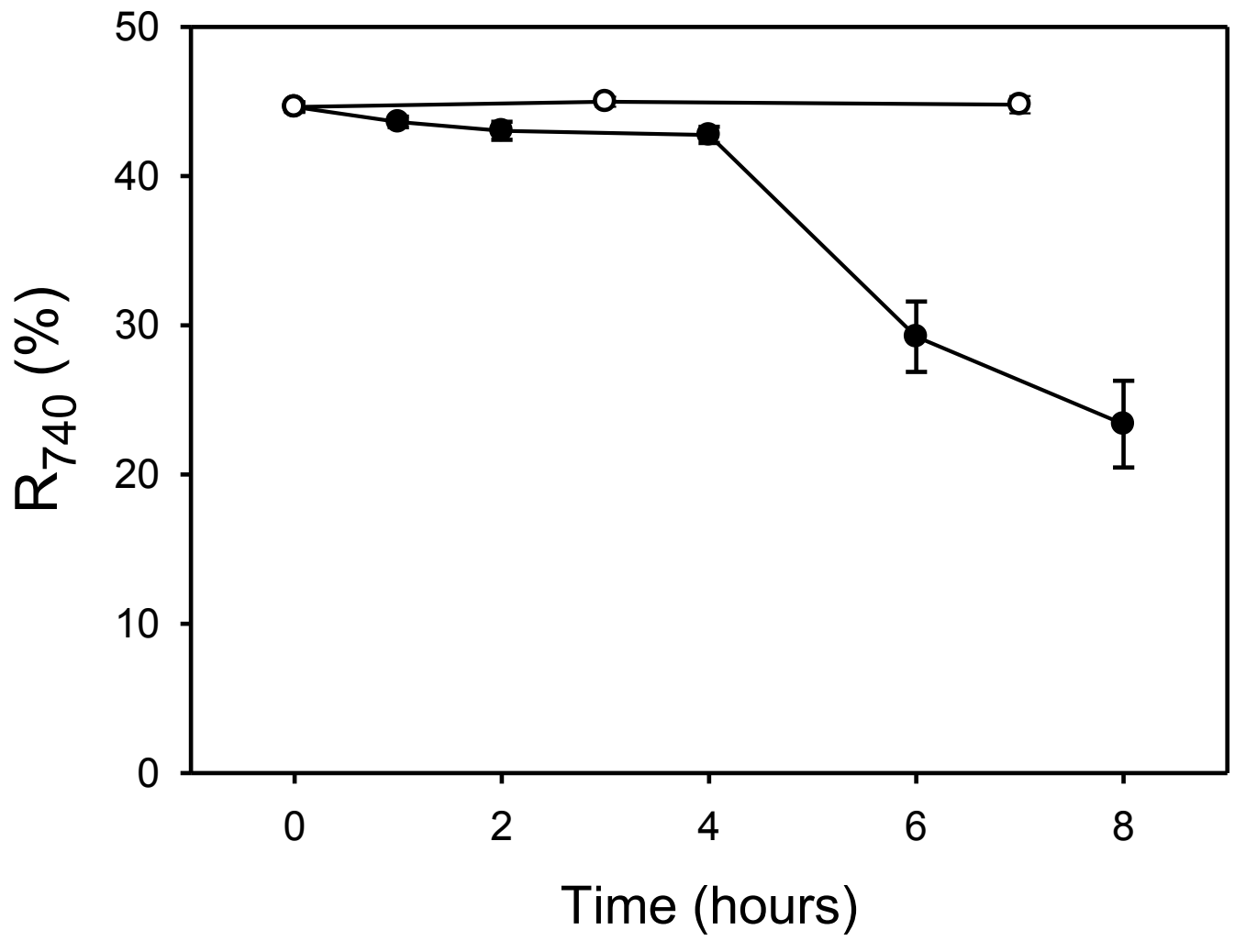

863

864

865

866

867

868

869

870

871

872

873

$874 \quad$ Figure $5 b$

875 


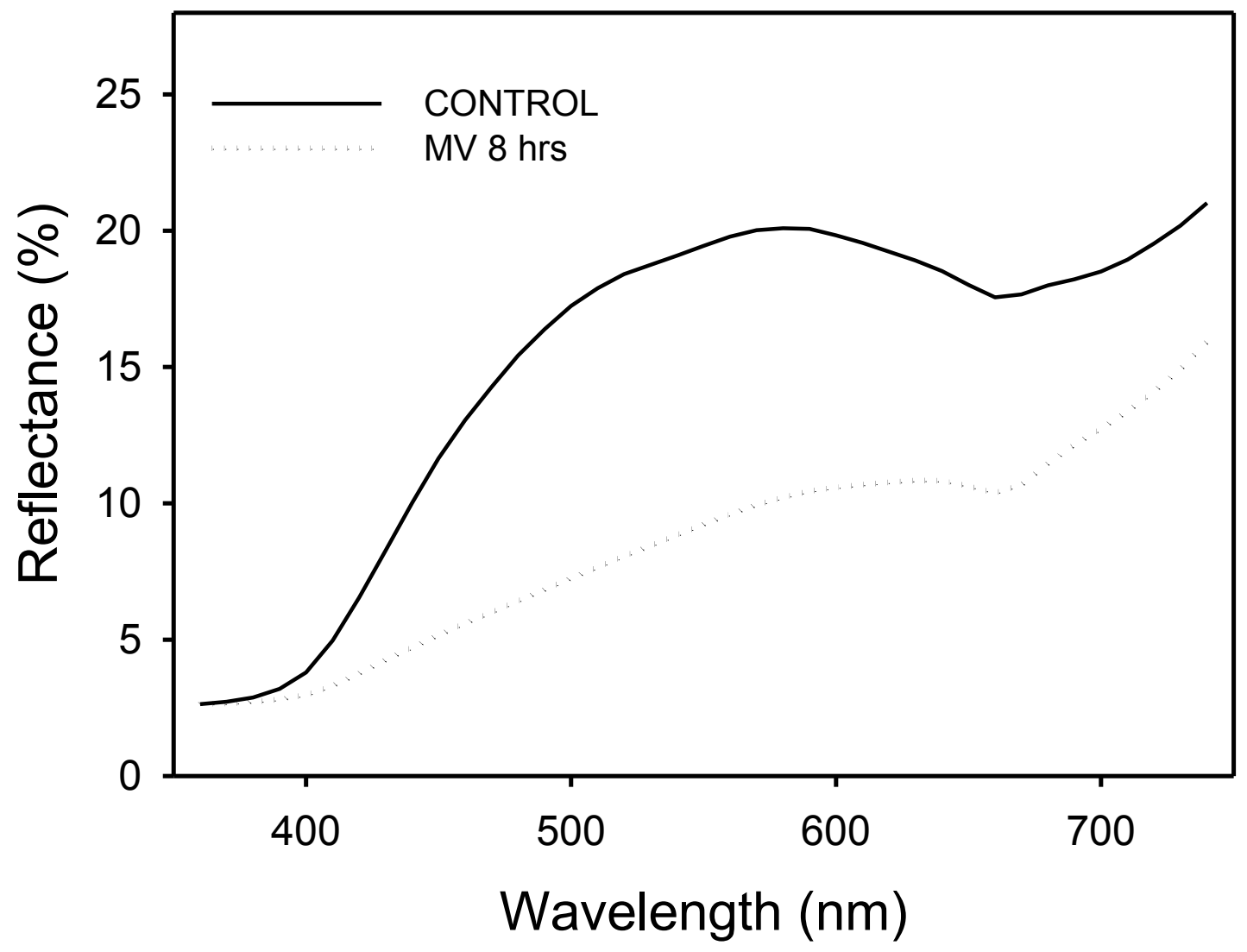

877

878

879

880

881

882

883

884

885

886

887 Fig. 6

888 


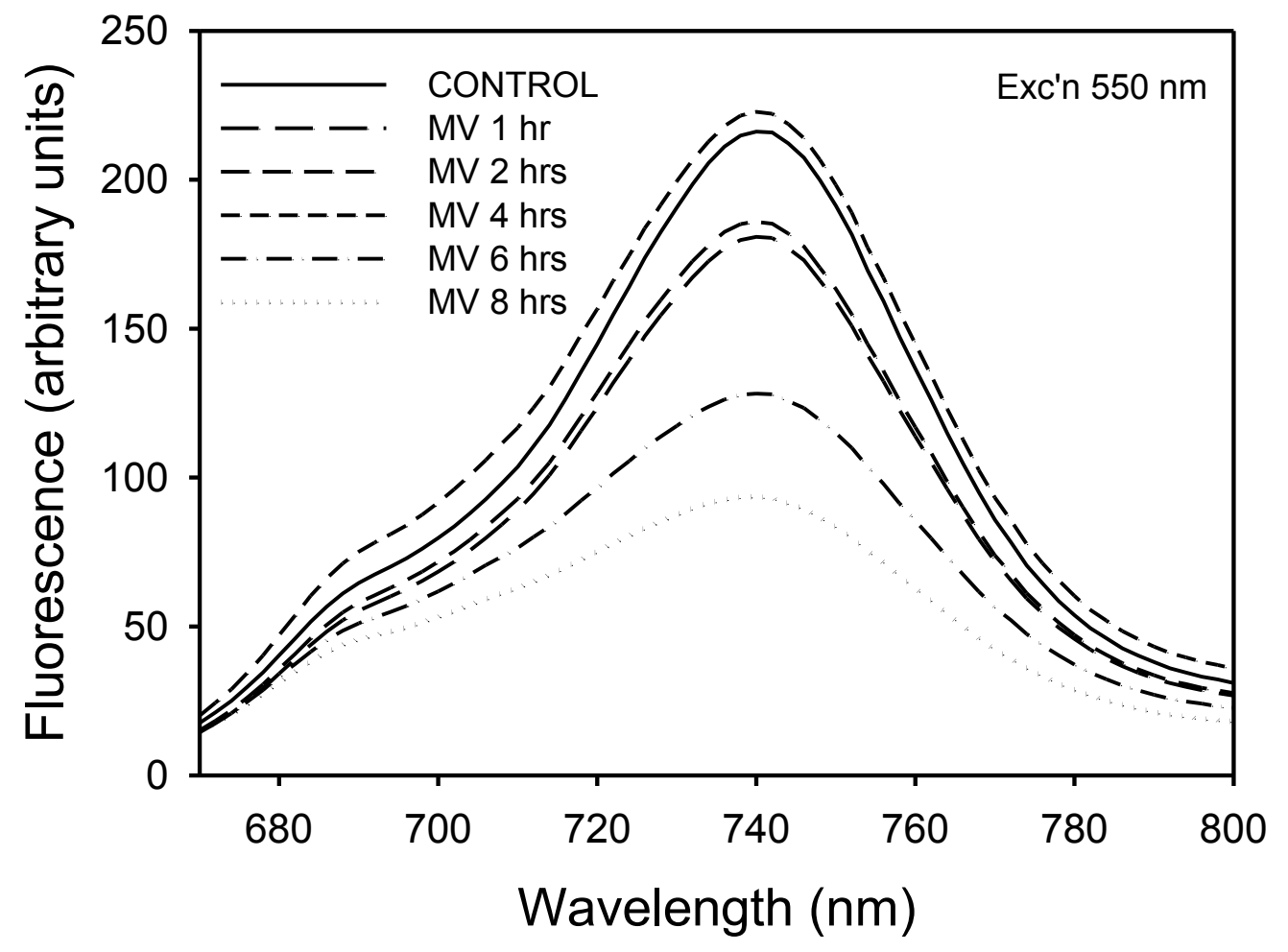




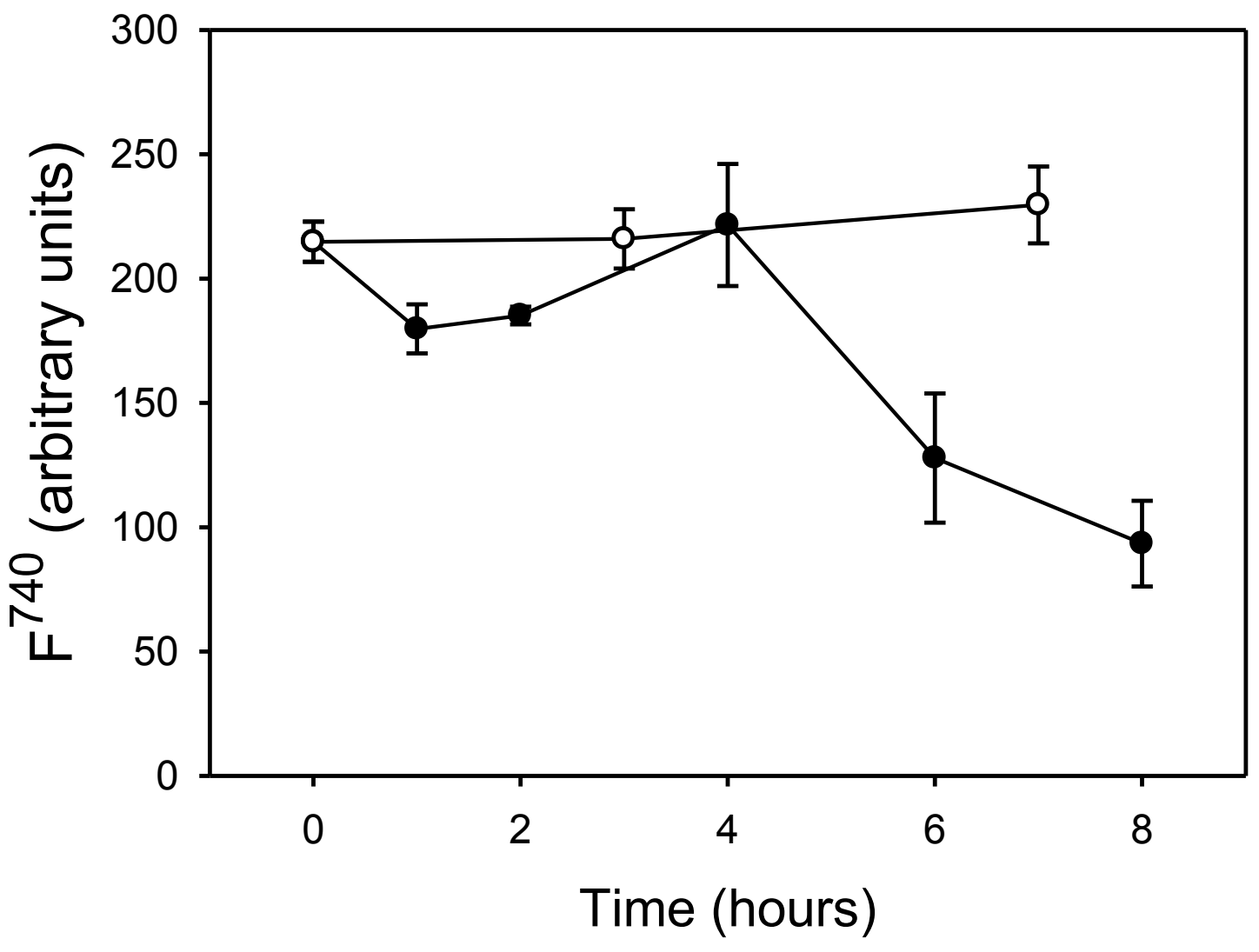

905

906

907

908

909

910

911

912

913

914

915 


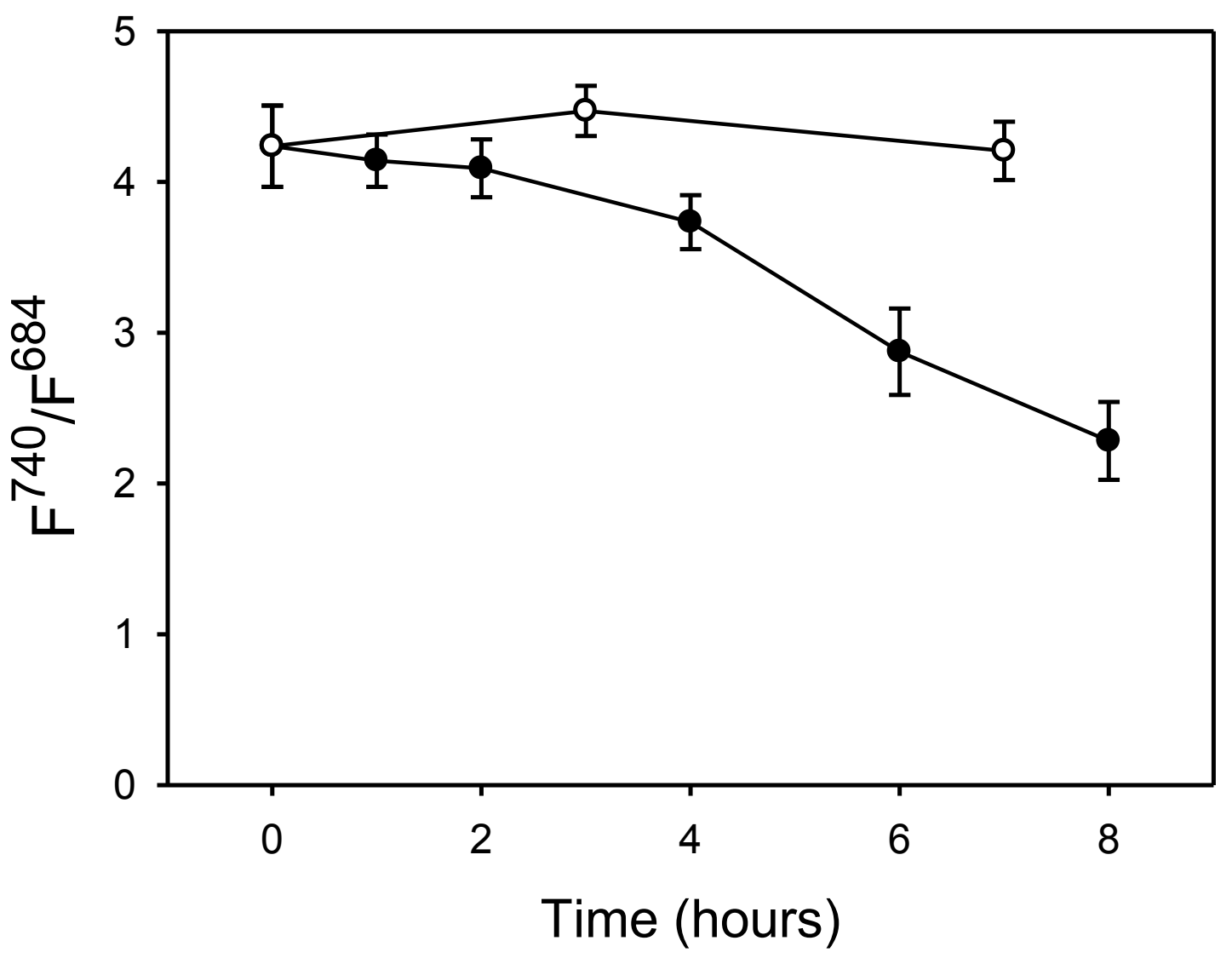




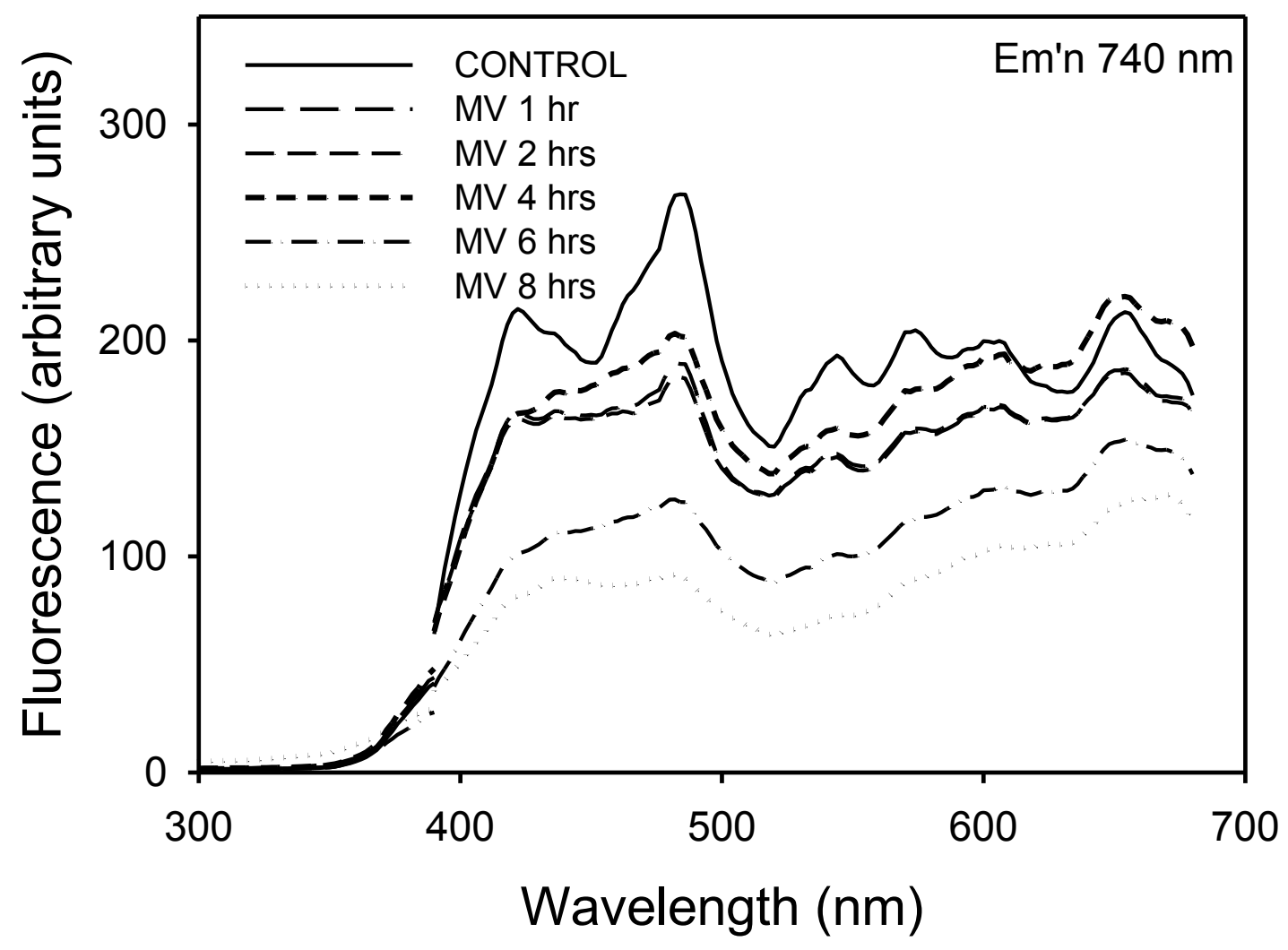

Fig. 8a 


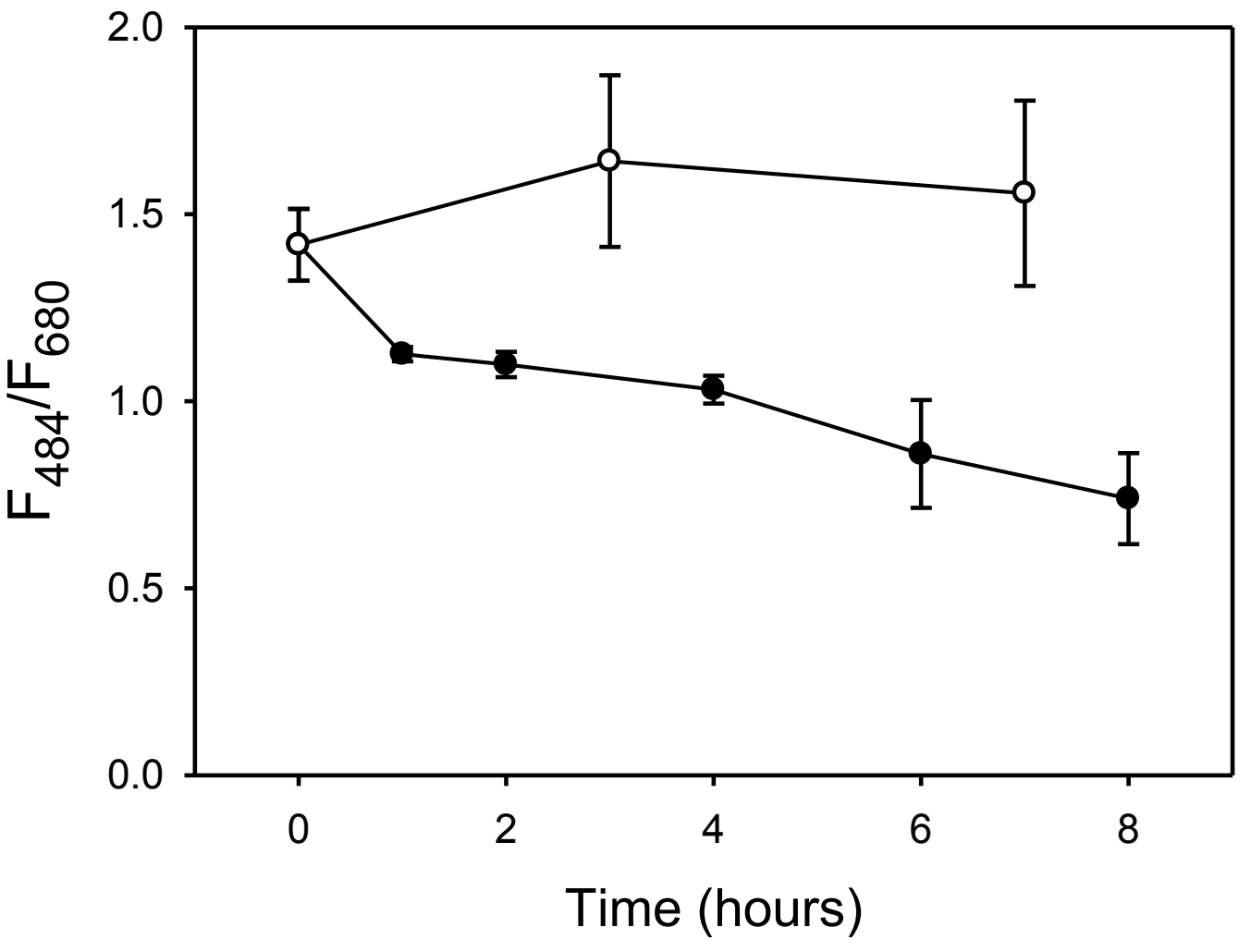

943

944

945

946

947

948

949

950

951

952 Fig. 8b 


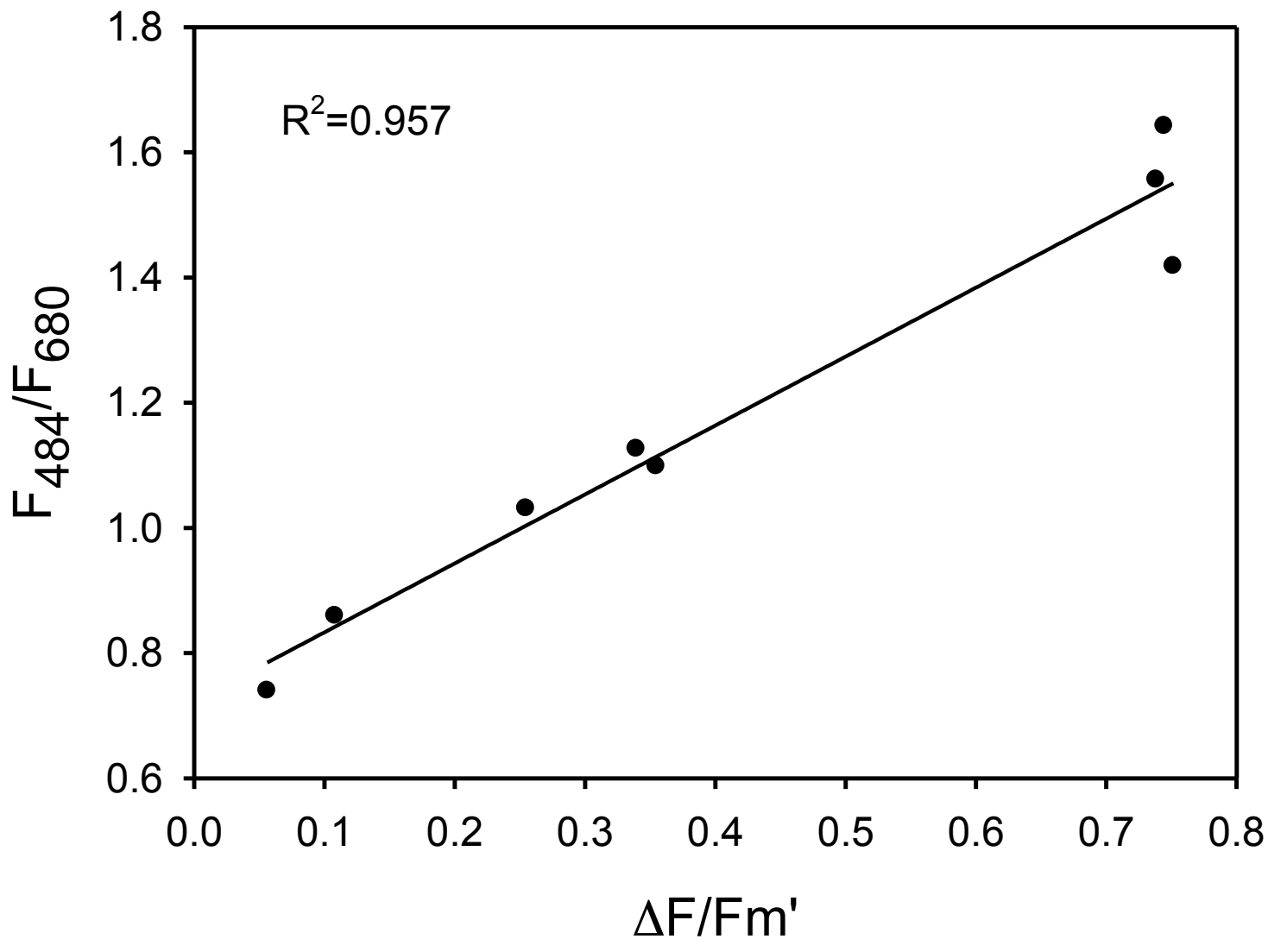

955

956

957

958

959

960

961

962

963

964 


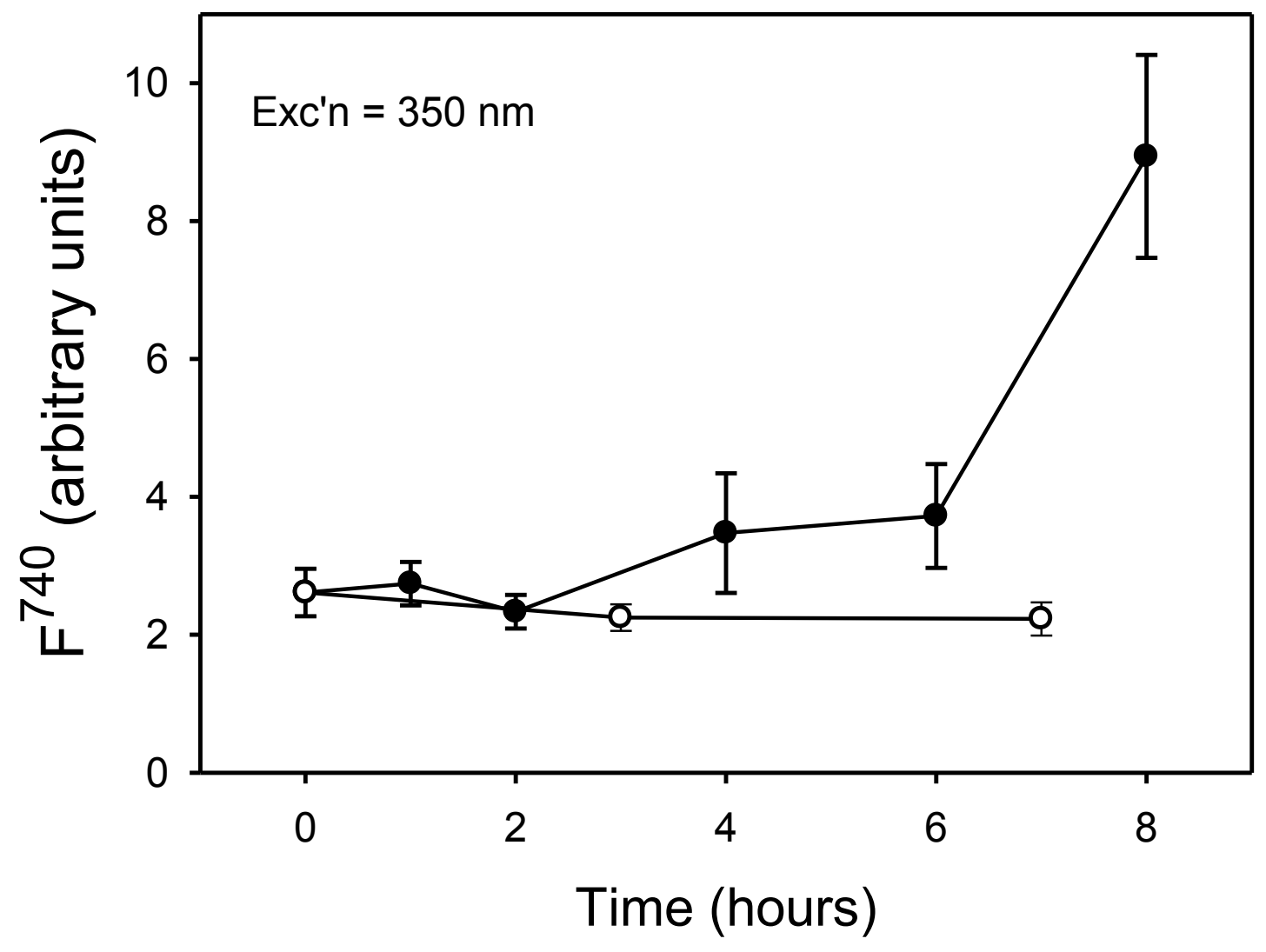

967 


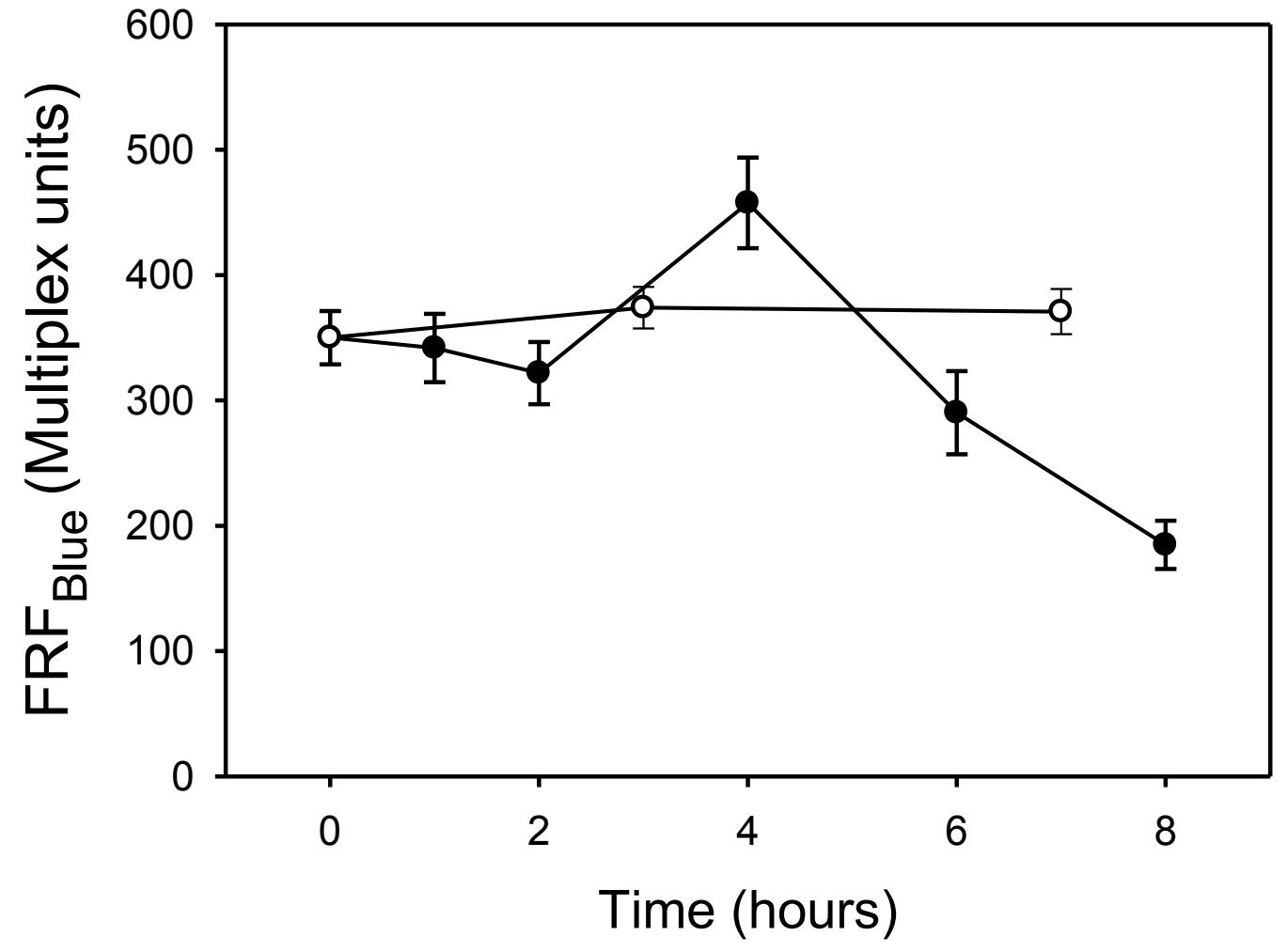

979

980

981

982

983

984

985

986

987

988

989 Fig. 9a

990 


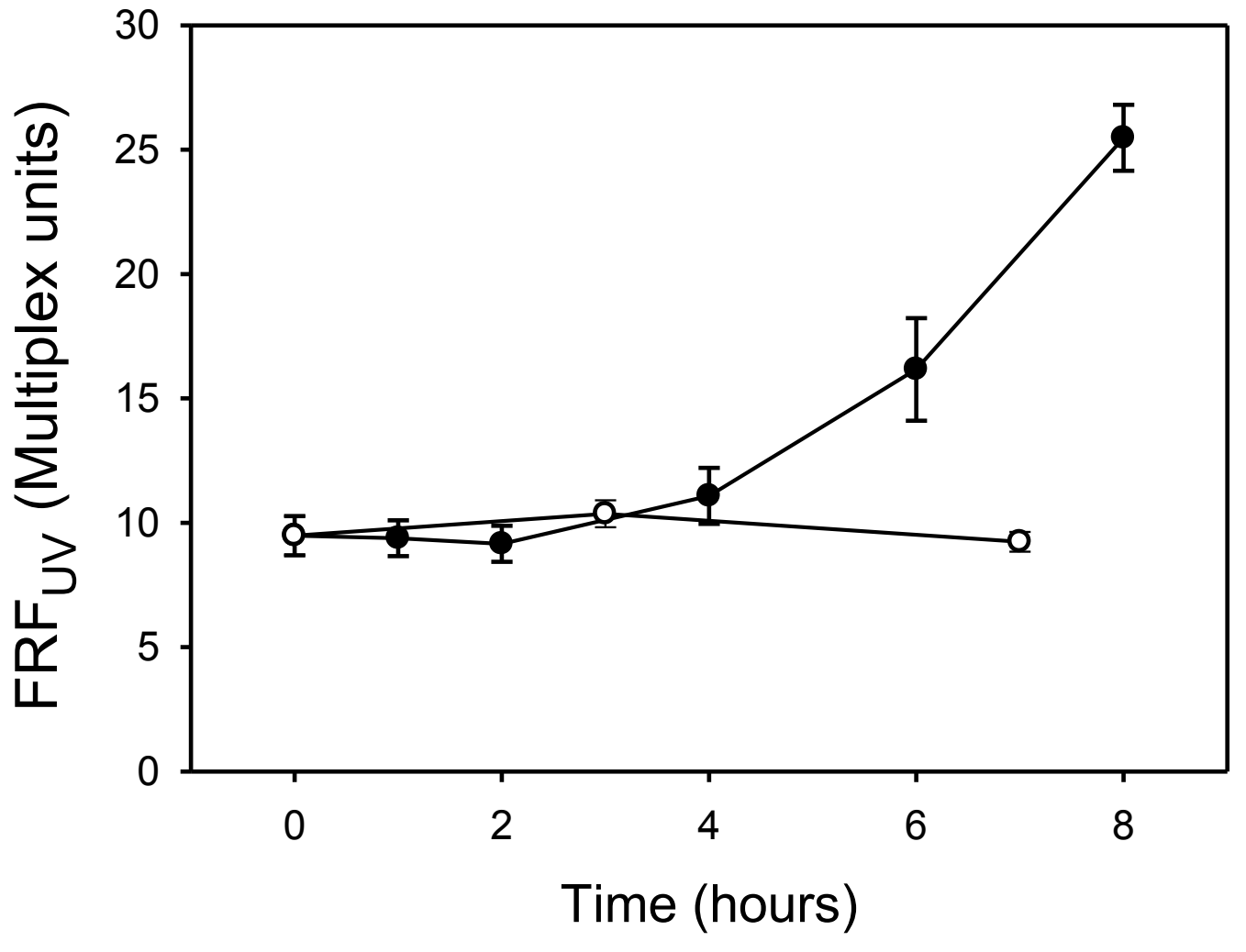

993

994

995

996

997

998

999

1000

1001 Figure 9b

1002 


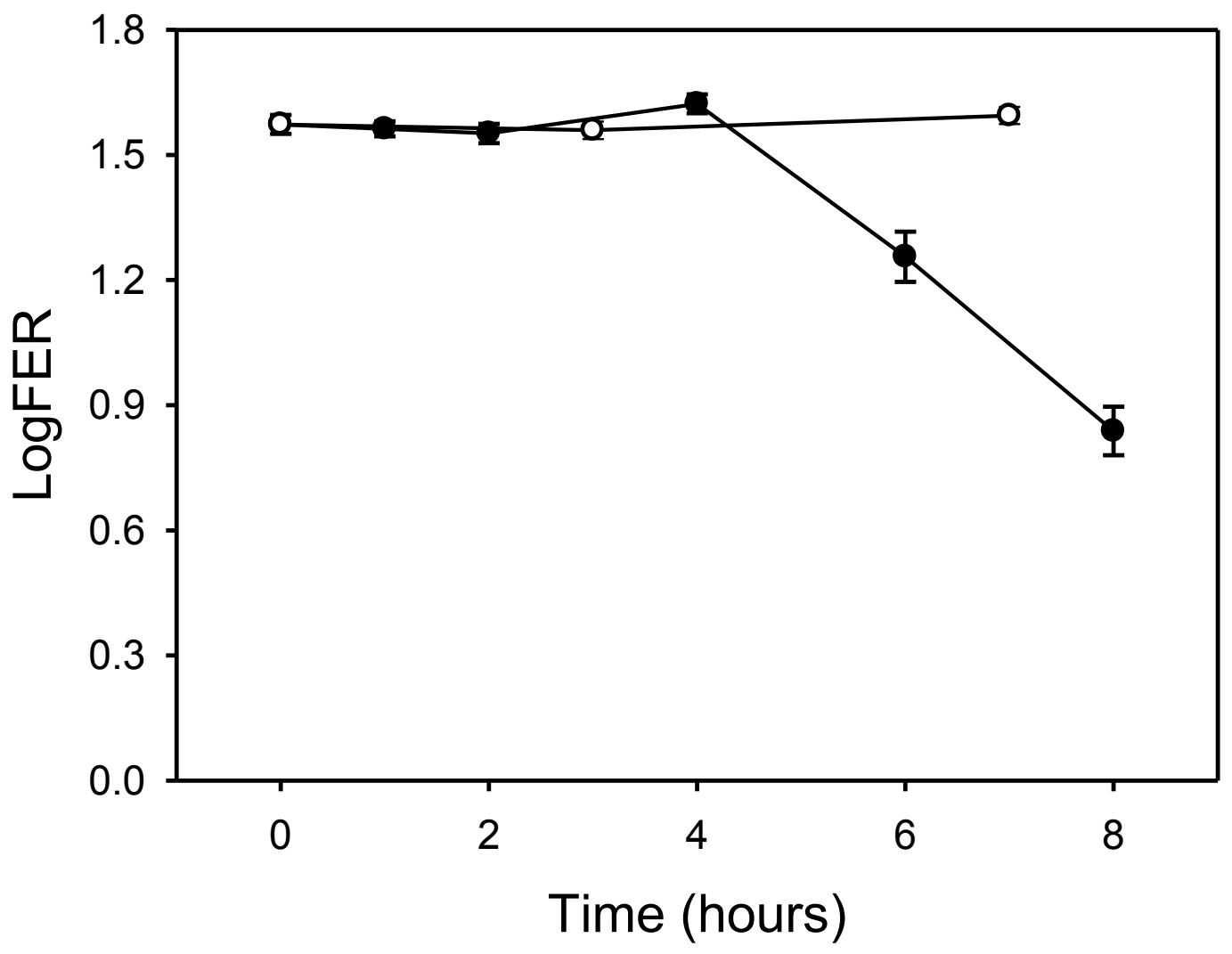

1004 Fig. 9c

1005 


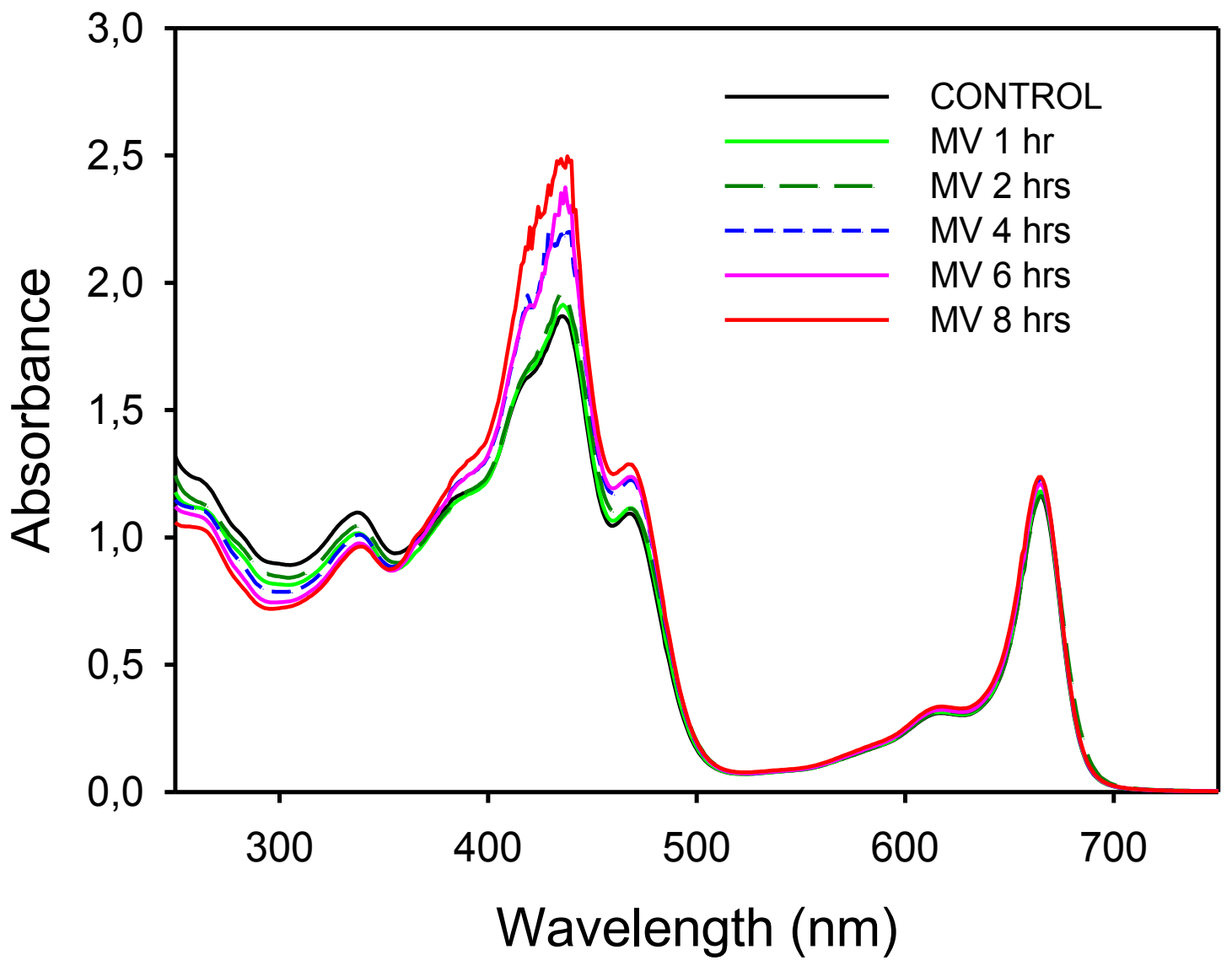

1008

1009

1010

1011

1012

1013

1014

1015

$1016 \quad$ Fig S1

1017 